\title{
A DINÂMICA SETORIAL E OS DETERMINANTES LOCACIONAIS DAS MICRORREGIÕES PAULISTAS
}

\author{
Admir Antonio Betarelli Junior * \\ Rodrigo Ferreira Simões ${ }^{\dagger}$
}

\begin{abstract}
Resumo
Este trabalho analisa as características das 63 microrregiões paulistas pela sua dinâmica setorial e pelos seus fatores locacionais no período de 2000 e 2010. Para tanto, utiliza o método diferencial-estrutural, na modificação de Esteban-Marquillas, Análise de Componentes Principais (ACP) e análise de cluster. Os principais resultados alcançados indicam que o processo de interiorização da atividade econômica, iniciado no final dos anos 1970, beneficiou as microrregiões de Campinas, São José dos Campos, Sorocaba, Ribeirão Preto, Santos (Baixada Santista) e Jundiaí, sendo estendido para as regiões circunvizinhas e formando aglomerações urbanas com vantagens locacionais e competitivas.
\end{abstract}

Palavras-chave: Fatores locacionais; Diferencial-estrutural; Interiorização da indústria; Análise Multivariada; São Paulo.

\begin{abstract}
The aim of this paper is to analyze the locational factors in State of São Paulo (Brazil) between 2000 and 2010. With micro-regional database, we apply a set of techniques: the method shift-share (Esteban-Marquillas variation), Principal Component Analysis (PCA) and Cluster Analysis. The main results indicate that the process of internalization of economic activities (began in the late 70s) has benefited the micro-regions of Campinas, São José dos Campos, Sorocaba, Ribeirão Preto, Santos and Jundiaí and this benefit was extended to the surrounding regions, building urban agglomerations of locational competitive advantages.
\end{abstract}

Keywords: Locational factors; Internalization of the industry; Shift-share; Multivariate Analysis; São Paulo (Brazil).

JEL classification: C02; R11

\footnotetext{
* Doutorando CEDEPLAR/UFMG

† Programa de Pós-graduação em Economia - CEDEPLAR/UFMG
} 


\section{Introdução}

O Estado de São Paulo detém a mais ampla e complexa rede urbana e industrial do país. Tal configuração se deve, em grande parte, dos efeitos econômicos observados desde o complexo cafeeiro. Nessa época já se observava efeitos geradores de economia de escala e de economias externas que expandiram o mercado e proporcionaram uma ampla acumulação do capital. Ademais, tais efeitos, verificados principalmente no meio urbano, foram responsáveis pela constituição de um potente mercado estruturado e espalhado no interior do Estado, privilegiando os pontos nodais da rede de transportes e comercialização do café. A configuração espacial à época já apresentava uma complexa e diversificada rede urbana, com articulações entre diversos subcentros regionais (Caiado 1995, Cano 1977).

Considerando que a industrialização e a urbanização sempre estiveram articuladas, a expansão da rede paulista de cidades seguiu acompanhada pelo processo de formação da indústria brasileira. A capital paulista passou a concentrar de forma crescente a produção industrial, transformando-se no maior polo de atração de migrantes e na maior metrópole do país. Com taxas anuais de crescimento populacional superiores às do Brasil desde 1940, o desempenho migratório adquiriu peso relevante para o comportamento observado em todo o período de concentração industrial (Caiado 1995). Aliás, conforme Lemos et al. (2003), a industrialização consolidou a hegemonia paulista e fez emergir uma hierarquia urbano-industrial extremamente desigual.

A concentração locacional da indústria paulista na Região Metropolitana de São Paulo (RMSP), em detrimento do interior, por volta da década de 1970, iniciou sua reversão num movimento conhecido como o processo de interiorização da indústria. Os investimentos industriais realizados em alguns municípios (com grandes encadeamentos de diversas atividades industriais), as ações em infraestrutura dos órgãos públicos (modernização do transporte rodoviário e ferroviário, isenções fiscais), a articulação da moderna agricultura com o setor industrial, aliado ao fato do grande mercado do Estado, tanto para insumos, bens intermediários e bens finais, foram as principais causas da interiorização do desenvolvimento (Cano 1992).

Diniz (1993); Diniz (1995); Diniz (2002) analisa as políticas macroeconômicas de caráter industrial e regional e aponta que a dinâmica econômica paulista, além do processo de reestruturação produtiva, promoveu uma desconcentração da indústria de transformação desde anos 1970. Esse processo foi denominado uma reversão da polarização da Região Metropolitana de São Paulo (RMSP). Além disso, o autor destaca ainda uma reconcentração metropolitana de atividades intensivas em ciência, tecnologia e conhecimento, pois essas necessitam de fatores locacionais densamente ofertados metropolitanamente, a saber: centros de ensino, pesquisa e desenvolvimento; disponibilidade de mão-de-obra diversificada e qualificada; infraestrutura de transporte e setor de serviços urbanos modernos; interdependências regionais integradas e facilidade para inovar.

No processo de interiorização, de acordo com Caiado (1995), verificou-se que os setores industriais mais dinâmicos, inicialmente localizados na capital e em seu entorno imediato, se direcionaram, atraídos por economias de aglomeração, às regiões de Campinas, Sorocaba, São José dos Campos e Baixada Santista. Juntas, tais regiões representavam 78,63\% do valor de transformação industrial (VTI) do interior em 1980. Esta afirmação pode ser comprovada ao 
verificarmos que a RMSP perdeu participação relativa no valor adicionado industrial, ou seja, de $64,1 \%$ para $58,1 \%$ no início de 1990 . Por outro lado, no interior observa-se que a região administrativa de Campinas aumentou sua participação de $15,1 \%$ para $19,2 \%$ do VTI no mesmo período. Com menos destaque estão às regiões administrativas de São José dos Campos (5,4\% para $6,3 \%$ ) e Sorocaba (de $4,0 \%$ para $4,9 \%$ ). A exceção a estas evidências corresponde ao declínio da composição do valor adicionado da Baixada Santista (de $4,3 \%$ para $2,6 \%$ ).

Em consonância com esse movimento, desde a década de 1970 constata-se que as taxas demográficas da região metropolitana de São Paulo arrefeceram, enquanto que no interior aceleraram. Dentre as regiões administrativas do interior, se destacam as de Campinas, do Vale do Paraíba, de Sorocaba, de Ribeirão Preto, de Bauru, de Franca, Barretos, Central, Registro e Santos (Seade 1992). Apesar disso, a dispersão do fluxo imigratório pelo interior não significou uma contra tendência no processo histórico de urbanização brasileiro, ou seja, os fluxos migratórios ocorreram no sentido rural-urbano ou urbanourbano. Os movimentos migratórios fortaleceram algumas cidades como polos de atração regional apresentando uma grande relação com seu desempenho regional (Patarra \& Baeninger 1994). As regiões de Santos, Sorocaba, São José dos Campos, Ribeirão Preto e Campinas são, como suas cidades vizinhas, as mais beneficiadas no processo de interiorização.

A reconfiguração espacial das atividades econômicas e da população no Estado de São Paulo levou para o interior um padrão de urbanização até então vigente somente na metrópole (capital) (Caiado 1995). Contudo, à medida que se estende o processo de concentração espacial das indústrias e da população, por meio das economias de aglomeração num processo circular cumulativo, intensificam também as deseconomias de aglomeração urbana (Pereira \& Lemos 2003).

Por sua vez, Azzoni (1986) relacionou o processo de interiorização com os fatores (des) aglomerativos no Estado de São Paulo. O autor apontou para um processo de espraiamento da indústria de transformação por meio de um campo aglomerativo da RMSP rumo às regiões do interior (por exemplo Campinas, São José dos Campos, Sorocaba, Santos e Jundiaí). Os seus resultados conclusivos indicaram que a articulação entre economias de urbanização em todas as regiões e o surgimento de deseconomias de aglomeração (i.e. custos locacionais crescente com o tamanho urbano) na cidade de São Paulo permitiu que as atividades industriais se localizem dentro de uma região que apresente vantagens aglomerativas extraídas das economias de proximidade. Dessa maneira, outras cidades, próximas a São Paulo, tornam-se também receptoras de uma complexa rede de serviços.

Embora o processo de interiorização, acentuado nos anos 1980 e 1990, tenha gerado uma desconcentração das atividades industriais e das taxas migratórias, existem discrepâncias e desigualdades regionais, essas com variado grau de industrialização e urbanização. Como decorrência disso, os fatores locacionais e a dinâmica econômica das regiões paulistas seguem a mesma lógica de tais assimetrias. Haddad \& Perobelli (2002) enfatizam que a heterogeneidade regional ocorre por vários aspectos, particularmente, pelas questões estruturais do setor produtivo e tributárias, pela disponibilidade dos recursos naturais, incentivos governamentais, custos inerentes ao transporte e facilidade ao mercado externo.

Por outro lado, conforme Lemos et al. (2003), o tratamento da dinâmica ur- 
bana a partir dos fatores aglomerativos e desaglomerativos possui uma grande corrente em economia regional, especialmente a partir dos trabalhos clássicos de Lösch (1954), que explica a própria constituição de um centro urbano em função das vantagens econômicas de aglomeração das atividades no espaço, e Von Thünen (1966), que analisa as forças desaglomerativas das atividades econômicas a partir de um centro urbano qualquer. À medida que a concentração das atividades intensifica-se no centro urbano, as forças desaglomerativas começam a agir como um contraste a este cenário (Leme 1982, Pereira 2002), sendo o principal fator desaglomerativo a "renda da terra" (renda fundiária diferencial).

As economias de aglomeração, por seu turno, podem ser classificadas em economias de escala (os custos unitários diminuem à medida que se expande a escala de produção da firma); economias de localização (devido à proximidade com outras firmas, os custos unitários de produção diminuem) e economia de urbanização (decorrentes da oferta de serviços no sítio onde há a localização da firma e também são externas a firmas). Além disso, podem também ser consideradas as economias de regionalização, representando um campo aglomerativo mais amplo que a urbanização (Azzoni 1986, Gonçalves et al. 2000).

É nesse mote de pesquisa que originam duas principais motivações de estudo para esse trabalho. Primeiro, observar e analisar a estrutura produtiva e as transformações competitivas das microrregiões paulistas entre 2000 a 2010, averiguando-se se tais regiões são especializadas e geram vantagens competitivas para as principais atividades setoriais (i.e. indústria, agropecuária e serviços). A caracterização das estruturas produtivas nas microrregiões paulistas contribui para as decisões dos planejadores públicos, na elaboração de políticas setoriais direcionadas para a diversificação das atividades em certas regiões (em direção aos setores dinâmicos). Isso se faz possível pois permite identificar, por exemplo, as microrregiões que apresentam problemas na sua estrutura produtiva (presença dominante de indústrias de crescimento lento) e detêm, ao mesmo tempo, efeitos competitivos e de alocação positivos.

Uma segunda motivação de estudo é a análise das economias aglomerativas e desaglomerativas das microrregiões do Estado de São Paulo, buscando associar tais aspectos locacionais com uma dinâmica setorial regional diferenciada. É possível, por exemplo, identificar regiões que detêm setores com grande efeitos de encadeamentos (economias de localização), um alto poder aquisitivo no mercado local (economia de urbanização), uma grande concentração de oferta de serviços produtivos e de força de trabalho qualificado (economia de urbanização), e alto nível de pobreza e analfabetismo (deseconomias urbanas). De forma condensada, esses aspectos econômicos podem ser visualizados por grupos de microrregiões, subsidiando a formulação de políticas públicas com o intuito de minimizar as desigualdades regionais no Estado de São Paulo. Pode-se, por exemplo, traçar estratégias de políticas regionais priorizando as microrregiões periféricas e não-industrializadas onde as deseconomias de urbanização predominam.

Portanto, em linhas gerais, o propósito desse artigo é caracterizar as $63 \mathrm{mi}$ crorregiões do Estado de São Paulo pela sua dinâmica setorial e pelos seus determinantes locacionais entre 2000 e 2010. Este trabalho difere-se dos autores supracitados por associar os resultados de vários métodos para períodos mais recentes da economia paulista, nas quais se conciliam análises das estruturas produtivas com fatores aglomerativos e desaglomerativos. Assumem-se nesse trabalho que as intervenções e investimentos públicos oriundos do processo 
de interiorização da indústria foram os principais determinantes históricos para a reestruturação produtiva e re-configuração do tecido urbano no Estado de São Paulo.

O trabalho utiliza o método diferencial-estrutural, na variante EstebanMarquillas, a fim captar os efeitos de alocação (vantagens competitivas e especialização). Em seguida, é aplicada a Análise de Componentes Principais (ACP) sobre um grande conjunto de indicadores locacionais (aglomerativos e desaglomerativos), uma vez que tal método possibilita extrair de forma condensada (reduzida) as características dos indicadores das microrregiões paulistas. Não obstante, a análise de cluster é também utilizada a fim de realizar uma tipologia de tais microrregiões. Além dessa seção introdutória, esse trabalho se organiza em mais 4 seções. A segunda seção apresenta uma breve discussão das metodologias utilizadas. Na terceira seção é apresentada a base de dados e variáveis. Na quarta seção são discutidos os resultados alcançados. Por fim, são tecidas as considerações finais, salientando as contribuições e os principais resultados desse trabalho.

\section{Metodologia}

\subsection{Método diferencial-estrutural}

O método diferencial-estrutural tem por finalidade descrever o crescimento econômico de uma região em termos da sua estrutura produtiva. Para tanto, por meio de um conjunto de identidades contábeis, o método aponta duas razões para o crescimento de uma região: a) a região pode crescer mais que as outras em virtude da sua composição produtiva ser dominada por setores dinâmicos ou $b$ ) porque a sua estrutura tem participação crescente no total das regiões, independente da existência de setores. Por essas razões, o crescimento regional é decomposto entre um componente estrutural e um componente diferencial (Haddad 1989).

Além desses componentes, Esteban-Marquillas introduz os efeitos alocação e competitivo, ao lado dos efeitos estruturais e diferenciais, para analisar os componentes do crescimento regional. Sua argumentação reside no fato que valores da variação diferencial no emprego regional não são devidos apenas ao comportamento do setor na região $\left(r_{i t}-r_{t t}\right)^{1}$, mas também ao grau de especialização do emprego regional nesse setor, ou seja, o efeito competitivo. Por outro lado, o crescimento regional pode estar oculto por transformações na variação competitiva, assim seu isolamento corresponde ao efeito alocação (Haddad 1989). Feitas essas observações, é possível formalizar o modelo de forma que o ano inicial (2000) será representado por 0 e o ano final (2010) corresponderá a 1. Os componentes do crescimento regional serão definidos como: variação regional $(R)$, variação estrutural $(E)$, variação diferencial $(D)$, efeito competitivo (C) e efeito de alocação (A). Dessa maneira segue:

\footnotetext{
${ }^{1}$ Taxa de crescimento do setor i no Estado (rit) e taxa de crescimento total do Estado de São Paulo $\left(r_{t t}\right)$.
} 


$$
\begin{aligned}
\underbrace{\sum_{i} E_{i q j}^{1}-\sum_{i} E_{i j}^{0}}_{V T}= \\
\underbrace{\sum_{i} E_{i j}^{0}\left(r_{t t}-1\right)}_{R}+\underbrace{\sum_{i} E_{i j}^{0}\left(r_{i t}-r_{t t}\right)}_{E}+\underbrace{\sum_{C} E_{i j}^{\prime 0}\left(r_{i j}-r_{i t}\right)}_{C} \\
+\underbrace{\sum_{i}\left[\left(E_{i j}^{0}-E_{i j}^{\prime 0}\right)\left(r_{i j}-r_{i t}\right)\right]}_{A}
\end{aligned}
$$

em que $V T=$ variação total, ou seja, a diferença entre o emprego do período final e inicial na região $j$;

Variação Total Líquida

$$
(V T L)=V T-R=E+C+A
$$

$R=$ acréscimo do emprego se a região $j$ tivesse a taxa de crescimento do emprego de todas as regiões;

$r_{t t}=\left(\sum_{i} \sum_{j} E_{i j}^{1}\right) / \sum_{i} \sum_{j} E_{i j}^{0}=$ crescimento do emprego de todas as regiões;

$r_{i t}=\sum_{j} E_{i j}^{1} / \sum_{j} E_{i j}^{0}=$ taxa do crescimento do emprego no setor $i$ em todas as regiões;

$r_{i j}=E_{i j}^{1} / E_{i j}^{0}=$ taxa de crescimento do emprego no setor $i$ da região $j$;

$E_{i j}^{\prime}=\sum_{i} E_{i j}\left(\sum_{j} E_{i j} / \sum_{i} \sum_{j} E_{i j}\right)=$ emprego homotético, isto é, emprego no setor se a região $j$ tivesse a mesma estrutura de emprego de São Paulo;

$$
D=C+A=\sum_{i} E_{i j}^{0}\left(r_{i t}-r_{i t}\right)
$$

Com a definição do efeito alocação, de acordo com Haddad (1989), é possível classificá-lo em quatro tipos de alternativas (Tabela 1).

Tabela 1: Alternativas de resultado para o efeito alocação

\begin{tabular}{lccc}
\hline Alternativas & Efeito Alocação & \multicolumn{2}{c}{ Componentes } \\
& & Especialização & $\begin{array}{l}\text { Vantagem } \\
\text { Competitiva }\end{array}$ \\
\hline $\begin{array}{l}\text { 1. Desvantagem Compe- } \\
\text { titiva, especializado }\end{array}$ & negativo & + & - \\
$\begin{array}{l}\text { 2. Desvantagem Compe- } \\
\text { titiva, não-especializado }\end{array}$ & positivo & - & - \\
$\begin{array}{l}\text { 3. Vantagem Competi- } \\
\text { tiva, não-especializado }\end{array}$ & negativo & - & + \\
$\begin{array}{l}\text { 4. Vantagem Competi- } \\
\text { tiva, especializado }\end{array}$ & positivo & + & + \\
\hline
\end{tabular}

Fonte: Haddad (1989) 


\subsection{Análise de Componentes Principais (ACP)}

O método de componentes principais constrói um conjunto de variáveis $Z_{1}$, $Z_{k}$, ortogonais (estatisticamente independentes) a partir de combinação linear de $k$-variáveis aleatórias $\left(X_{1}, \ldots, X_{k}\right)$. Essas variáveis ortogonais, denominadas componentes principais, não são correlacionadas entre si, e captam toda a variabilidade das variáveis originais, ou seja, as variáveis ortogonais são definidas a partir de uma matriz de covariância. Os componentes principais permitem reduzir e classificar os dados originais mantendo maior parte das informações (Andrade 1989, Mingoti 2007). Formalmente, as combinações lineares são expressas como:

$$
\begin{aligned}
& Z_{1}=a_{1}^{\prime} X=a_{11} X_{1}+\cdots+a_{1 k} X_{k} \\
& \vdots \\
& Z_{k}=a_{k}^{\prime} X=a_{k 1} X_{1}+\cdots+a_{k k} X_{k}
\end{aligned}
$$

Essas combinações não são correlacionadas (ortogonais) e atingem maiores variâncias possíveis. Em outras palavras, as combinações lineares maximizam $\operatorname{Var}\left(Z_{1}\right)$ e $\operatorname{Var}\left(Z_{k}\right)$ sujeito a $a_{1}^{\prime} X=a_{k}^{\prime} X=1$. Cada variância é definida como:

$$
\operatorname{Var}\left(Z_{i}\right)=a_{i}^{\prime} C a_{i}
$$

em que

$$
C=\left[\begin{array}{ccc}
c_{11} & \cdots & c_{1 k} \\
\vdots & \ddots & \vdots \\
c_{k 1} & \cdots & c_{k k}
\end{array}\right]
$$

é uma matriz de correlação.

Além disso, as variáveis ortogonais são calculadas a partir dos pesos $a_{i k}$ de forma que o primeiro componente $\left(Z_{1}\right)$ corresponda a maior parcela da variabilidade das variáveis originais e, assim, sucessivamente, o que permite que $\operatorname{Var}\left(Z_{1}\right) \geq \cdots \geq \operatorname{Var}\left(Z_{k}\right)$.

Manly (1986) descreve os seguintes passos para a operacionalização do método de componentes principais, como segue:

a) Inicia-se a padronização das variáveis originais $\left(X_{1}, \ldots, X_{k}\right)$, ou seja:

b) Calcula-se a matriz de correlação $(C)$; e

c) Encontra-se os autovalores $\left(\lambda_{1}, \ldots, \lambda_{k}\right)$ e seus autovetores $\left(a_{1}, \ldots, a_{k}\right)$ respectivos.

d) E, seleciona-se um número de componentes que considere uma proporção adequada da variação dos dados para o tipo de problema em questão.

\subsection{Análise de cluster}

A análise de cluster é por natureza uma análise exploratória que busca identificar grupos similares dentro de uma amostra maior. Nesses termos, com tal análise é possível sintetizar o número de dados, apontar os valores extremos (outliers) e sugerir hipóteses sobre a relação das variáveis. O seu algoritmo agrupa os indivíduos (no nosso caso microrregiões) similares em categorias 
iguais a partir $k$ variáveis associadas (Manly 1986). O critério de agrupamento dos indivíduos se dá com base na sua proximidade, indicada por uma métrica de similaridade. Aqui utilizamos a mais usual, a saber, a distância euclidiana, que é expressa da seguinte forma:

$$
d_{i j}=\sqrt{\sum_{k=1}^{p}\left(x_{i k}-x_{j k}\right)^{2}}
$$

A análise de cluster é subdividida em uma abordagem hierárquica e uma de partição. Nesse trabalho será adotado exclusivamente o método hierárquico e aglomerativo, o que significa dizer que os indivíduos são agrupados sequencialmente de acordo com suas semelhanças, formando subgrupos e grupos de acordo com as influencias das suas similaridades encontradas em cada estágio.

\section{Base De Dados E Tratamento Das Variáveis}

A base de dados utilizada para o estudo das 63 microrregiões paulistas corresponde ao emprego efetivo por atividades econômicas de 2000 e 2010 da Relação Anual de Informações Sociais (RAIS). O intervalo de tempo escolhido se justifica por tratar-se do período mais recente para os dados do Estado de São Paulo, sendo 10 anos um período razoavelmente longo para captar as recentes mudanças na estrutura produtiva das microrregiões paulistas. A utilização de dados mais recentes disponível na RAIS valoriza os resultados da caracterização econômica das microrregiões paulistas. Vale destacar que a principal vantagem da RAIS é o nível detalhado de desagregação geográfica e setorial dos dados. Sua limitação, contudo, reside principalmente na exclusiva cobertura de emprego formal e dos estabelecimentos com mais de cinco empregados registrados.

Dessa maneira, para a aplicação do método shift-share, tanto quanto algumas medidas clássica de localização e especialização, serão adotados os dados de emprego efetivo da indústria (classificação do IBGE). Por outro lado, para analisar os fatores aglomerativos e desaglomerativos das microrregiões paulistas, por meio da Análise de Componentes Principais (ACP), foram desenvolvidas variáveis proxies $^{2}$ com base nos dados de emprego efetivo de 2010 da RAIS sob referência dos trabalhos de Pereira \& Lemos (2003), Lemos et al. (2003), Pereira (2002) e Martins (2003). A Tabela 2 apresenta as 12 variáveis selecionadas.

\section{Resultados E Discussões}

É importante, antes de discutir os resultados alcançados pelo método shiftshare, realizar uma análise descritiva dos dados extraídos da RAIS a fim de apontar possíveis concentrações por grupos de atividade econômica das microrregiões paulistas. A Tabela 1 exibe as microrregiões com participações mais proeminentes na composição setorial de emprego efetivo no anos de 2000 e 2010.

\footnotetext{
${ }^{2}$ Correspondem 12 variáveis filtradas após os resultados da matriz de correlação.
} 


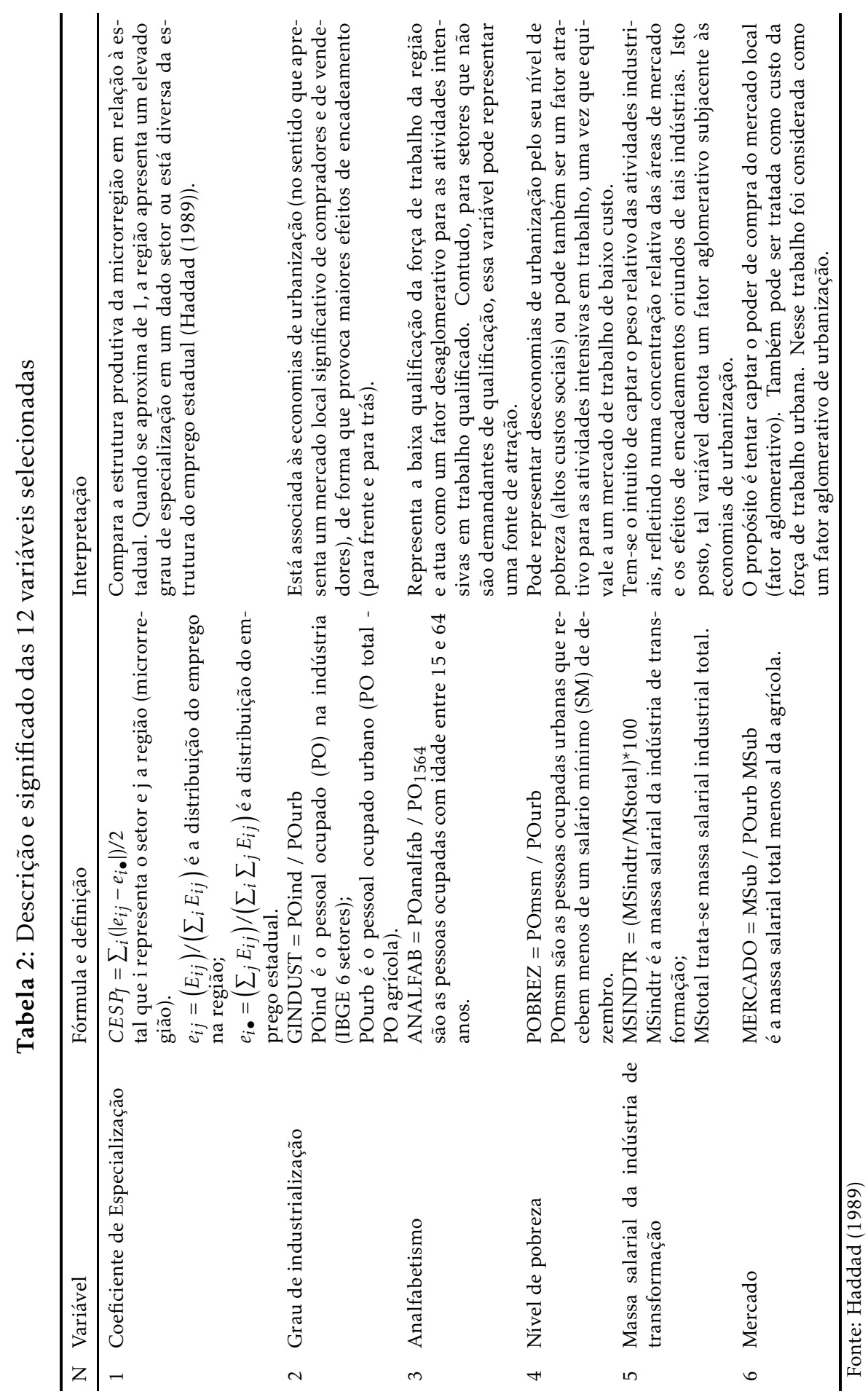




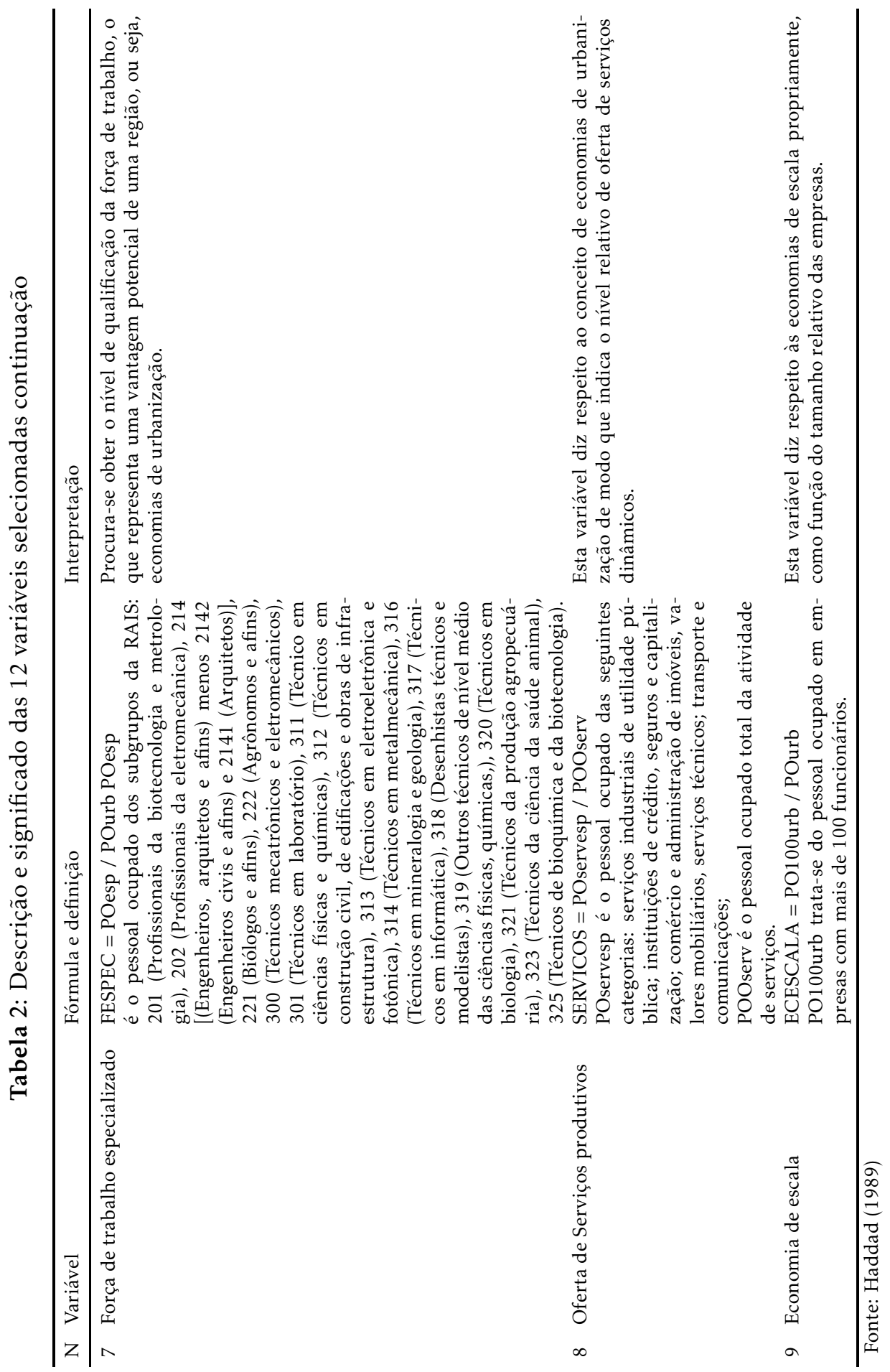




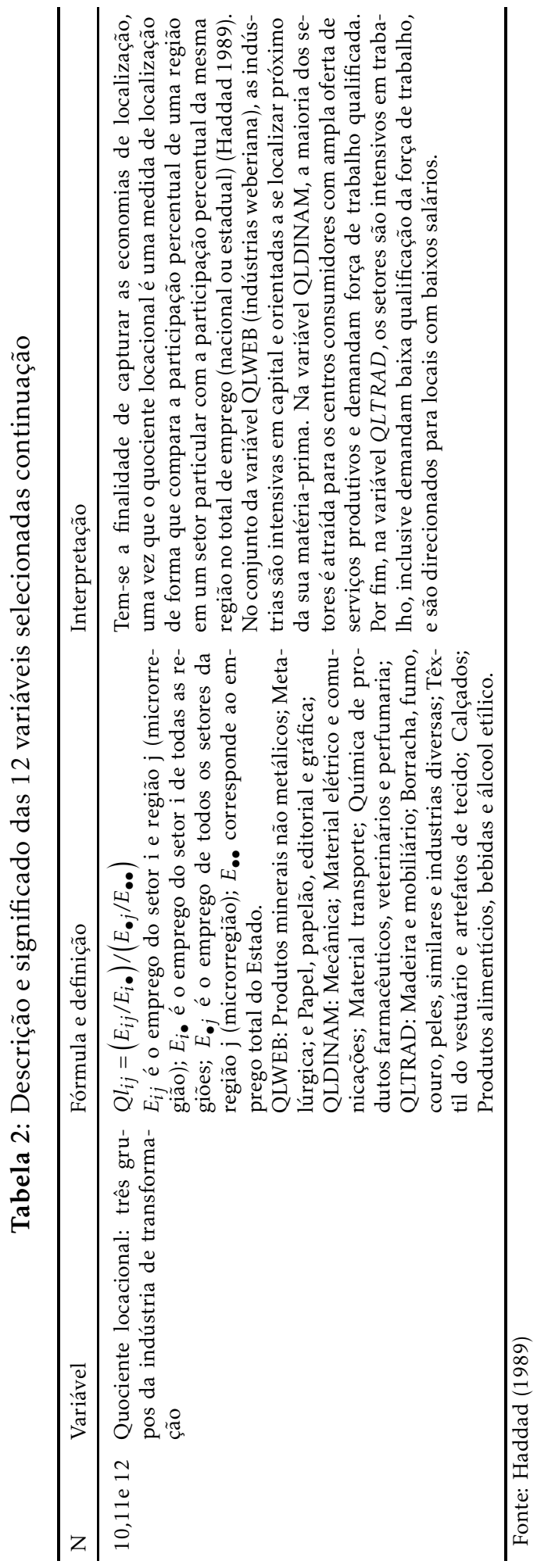


Tabela 3: Participações do emprego efetivo no Estado de São Paulo

\begin{tabular}{|c|c|c|c|c|c|c|c|c|c|c|}
\hline \multirow[t]{2}{*}{ Microrregiões } & \multicolumn{2}{|c|}{ Indústria } & \multicolumn{2}{|c|}{ Serviços } & \multicolumn{2}{|c|}{ Agropecuária } & \multicolumn{2}{|c|}{$\begin{array}{l}\text { Demais } \\
\text { Atividades }\end{array}$} & \multicolumn{2}{|c|}{ Total } \\
\hline & 2000 & 2010 & 2000 & 2010 & 2000 & 2010 & 2000 & 2010 & 2000 & 2010 \\
\hline Araraquara & 0.01 & 0.02 & 0.01 & 0.01 & 0.07 & 0.05 & 0.01 & 0.01 & 0.01 & 0.01 \\
\hline Bauru & 0.01 & 0.01 & 0.01 & 0.01 & 0.03 & 0.03 & 0.01 & 0.02 & 0.01 & 0.01 \\
\hline Bragança Paulista & 0.01 & 0.02 & 0.01 & 0.01 & 0.02 & 0.02 & 0.01 & 0.01 & 0.01 & 0.01 \\
\hline Campinas & 0.08 & 0.09 & 0.05 & 0.06 & 0.03 & 0.03 & 0.07 & 0.07 & 0.06 & 0.07 \\
\hline Franca & 0.01 & 0.01 & 0.00 & 0.00 & 0.01 & 0.02 & 0.01 & 0.01 & 0.01 & 0.01 \\
\hline Guarulhos & 0.05 & 0.05 & 0.02 & 0.02 & 0.00 & 0.00 & 0.02 & 0.03 & 0.03 & 0.03 \\
\hline Itaperica da Serra & 0.02 & 0.02 & 0.02 & 0.02 & 0.00 & 0.00 & 0.02 & 0.02 & 0.02 & 0.02 \\
\hline Jaboticabal & 0.01 & 0.01 & 0.01 & 0.01 & 0.06 & 0.03 & 0.01 & 0.01 & 0.01 & 0.01 \\
\hline Jaú & 0.01 & 0.01 & 0.00 & 0.00 & 0.04 & 0.02 & 0.01 & 0.01 & 0.01 & 0.01 \\
\hline Jundiaí & 0.02 & 0.03 & 0.01 & 0.01 & 0.00 & 0.00 & 0.02 & 0.02 & 0.01 & 0.02 \\
\hline Limeira & 0.02 & 0.02 & 0.01 & 0.01 & 0.02 & 0.02 & 0.01 & 0.01 & 0.01 & 0.01 \\
\hline Mogi das Cruzes & 0.03 & 0.03 & 0.02 & 0.02 & 0.02 & 0.02 & 0.02 & 0.02 & 0.02 & 0.02 \\
\hline Mogi Mirim & 0.01 & 0.01 & 0.01 & 0.01 & 0.02 & 0.03 & 0.01 & 0.01 & 0.01 & 0.01 \\
\hline Osasco & 0.04 & 0.04 & 0.05 & 0.05 & 0.00 & 0.00 & 0.04 & 0.04 & 0.04 & 0.05 \\
\hline Piracicaba & 0.02 & 0.02 & 0.01 & 0.01 & 0.01 & 0.01 & 0.01 & 0.01 & 0.01 & 0.01 \\
\hline Presidente & 0.01 & 0.01 & 0.01 & 0.01 & 0.02 & 0.02 & 0.01 & 0.01 & 0.01 & 0.01 \\
\hline \multicolumn{11}{|l|}{ Prudente } \\
\hline Ribeirão Preto & 0.02 & 0.02 & 0.02 & 0.02 & 0.06 & 0.03 & 0.03 & 0.03 & 0.02 & 0.02 \\
\hline Santos & 0.01 & 0.01 & 0.04 & 0.03 & 0.00 & 0.00 & 0.03 & 0.03 & 0.03 & 0.03 \\
\hline São João da & 0.01 & 0.01 & 0.01 & 0.00 & 0.05 & 0.05 & 0.01 & 0.01 & 0.01 & 0.01 \\
\hline \multicolumn{11}{|l|}{ Boa Vista } \\
\hline São José do & 0.01 & 0.02 & 0.01 & 0.01 & 0.03 & 0.03 & 0.02 & 0.02 & 0.01 & 0.02 \\
\hline \multicolumn{11}{|l|}{ Rio Preto } \\
\hline São José dos & 0.01 & 0.02 & 0.01 & 0.01 & 0.03 & 0.03 & 0.02 & 0.02 & 0.01 & 0.02 \\
\hline \multicolumn{11}{|l|}{ Campos } \\
\hline São Paulo & 0.37 & 0.30 & 0.55 & 0.53 & 0.02 & 0.02 & 0.45 & 0.42 & 0.46 & 0.44 \\
\hline Sorocaba & 0.04 & 0.04 & 0.02 & 0.02 & 0.02 & 0.02 & 0.03 & 0.03 & 0.03 & 0.03 \\
\hline Demais & 0.13 & 0.15 & 0.10 & 0.10 & 0.45 & 0.54 & 0.13 & 0.13 & 0.13 & 0.13 \\
\hline \multicolumn{11}{|l|}{ Microrregiões } \\
\hline Total & 1.00 & 1.00 & 1.00 & 1.00 & 1.00 & 1.00 & 1.00 & 1.00 & 1.00 & 1.00 \\
\hline Total & 1935 & 2900 & 4172 & 6502 & 313 & 331 & 1629 & 3140 & 8050 & 12874 \\
\hline Empregos (mil) & & & & & & & & & & \\
\hline
\end{tabular}

Nota-se que as microrregiões de São Paulo, Campinas, Osasco, São José dos Campos, Santos, Sorocaba e Guarulhos correspondem juntas a 67\% (2010) e $68 \%$ (2000) do total de empregos efetivos. Caracteristicamente são microrregiões com maiores graus de urbanização e estão situadas na região metropolitana expandida do Estado de São Paulo. Tendo em vista que a urbanização está articulada com o setor industrial e associada ao setor de serviços, observamos que estes dois setores representam juntos aproximadamente $75 \%$ (24\% da indústria e $51 \%$ de serviços) do total de empregos do Estado em 2000 . Esse cenário permanece em 2010, com um percentual por volta de 73\% (23\% da indústria e $50 \%$ de serviços). Do total da indústria e dos serviços, essas microrregiões alcançam em conjunto, respectivamente, 61\% e 74\% (aproximadamente).

$\mathrm{Na}$ atividade da agropecuária, que representa aproximadamente $4 \%$ do emprego paulista, observa-se que as microrregiões de São João da Boa Vista, Araraquara, São José do Rio Preto, Jaboticabal, Bauru, Ribeirão Preto, Mogi Mirim e Campinas se destacam na distribuição de emprego (cerca de 35\% em 2000 e $27 \%$ em 2010). Todavia, quando se analisa a composição de emprego 
dessas microrregiões, verifica-se que em Bauru, Ribeirão Preto e São José do Rio Preto, o setor industrial e de serviços são o que mais empregam, em torno de $65 \%$ do total de emprego.

De modo geral, as participações das microrregiões sobre o emprego total da economia paulista, listadas na Tabela 1 , demonstram poucas mudanças no período de 2000 a 2010. Entretanto, quando se verifica a distribuição do emprego por grupo de setor entre as microrregiões, constata-se uma maior assimetria de participação. Como forma de ilustrar tais assimetrias entre as microrregiões, a Figura1 ilustra a distribuição percentual acumulada do emprego por atividades.
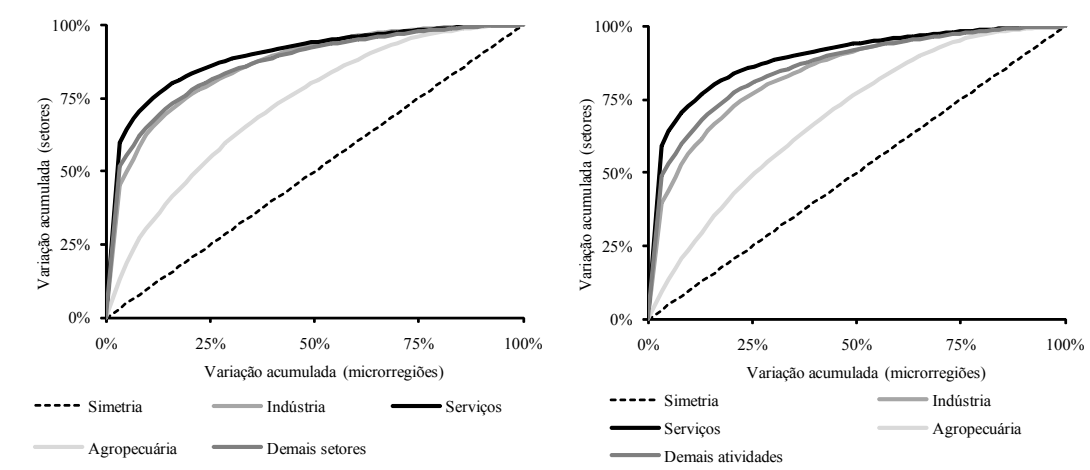

Fonte: Elaboração própria a partir dos dados da RAIS.

Figura 1: Distribuição percentual acumulada do emprego por grupo de atividades

Observa-se que a distribuição do emprego por setor entre as microrregiões paulistas é desigual, principalmente quando analisado o setor de serviços e outras atividades (construção civil e comércio). Por outro lado, a agropecuária revela uma distribuição menos assimétrica frente aos demais setores. Ademais, constata-se que as mudanças entre 2000 e 2010 foram relativamente tímidas. Para obter uma melhor análise da localização dos setores entre os períodos, é interessante analisar outras duas medidas: coeficiente de redistribuição (medida de localização) e coeficiente de reestruturação (medida regional).

O coeficiente de redistribuição relaciona a distribuição percentual de emprego de um mesmo setor entre dois períodos. Este coeficiente tem por finalidade averiguar se o setor está dispersando ou se concentrando no espaço entre os dois períodos. Formalmente:

$$
C R_{J}=\left[\sum_{j}\left(\left.\right|_{j} e_{i}^{t=1}-{ }_{j} e_{i}^{t=0} \mid\right)\right] / 2
$$

em que $0 \leq C R_{J} \leq 1 ; \mathrm{e}_{j} e_{i}^{t}=E_{i j}^{t} / \sum_{j} E_{i j}^{t}$ é a distribuição percentual do emprego setorial entre as regiões.

Se o valor destes coeficientes se aproximar de zero significa que não houve mudanças significativas no padrão espacial de localização do setor (Haddad 1989). Nesses termos, ao se calcular esse coeficiente, observou-se que os resultados estão condizentes com o apresentado na Figura1. Em outras palavras, a indústria $(0,079)$, a construção civil $(0,072)$, o comércio $(0,043)$, o setor de 
serviços $(0,037)$ e a agropecuária $(0,137)$ apresentam um padrão espacial com inexpressivas mudanças entre os períodos, uma vez que seus coeficientes foram próximos de zero. Dessa maneira, a indústria e o setor de serviços, que eram concentradas em 2000, se mantiveram em 2010.

Pode-se também observar as mudanças na estrutura do emprego numa região entre os dois períodos. Para tanto, calcula-se o coeficiente de reestruturação da região. Este coeficiente relaciona a estrutura do emprego na região $j$ entre dois períodos com o objetivo de avaliar o grau de mudança na especialização desta região.

$$
C T_{i}=\left[\sum_{j}\left(\left|{ }_{i} e_{j}^{t=1}-{ }_{i} e_{j}^{t=0}\right|\right)\right] / 2
$$

em que $0 \leq C T_{i} \leq 1 ; \mathrm{e}_{i} e_{j}^{t}=E_{i j}^{t} / \sum_{i} E_{i j}^{t}$ é a distribuição percentual do emprego na região.

Se este coeficiente for igual ou próximo de 0 , menor será a mudança na composição setorial da região. Por outro lado, se for próximo de 1, terá ocorrido uma reestruturação profunda na composição setorial da região. Todos os resultados se aproximam de zero. Apenas as microrregiões de Piedade $(0,44)$, Jaboticabal $(0,16)$ e Araraquara $(0,15)$ exibiram um grau de mudança estrutural sensivelmente maior. Dentre essas microrregiões, em Piedade as mudanças ocorreram, sobretudo, em três setores: comércio, serviços e agropecuária. Nas microrregiões de Jaboticabal estão envolvidas com os setores da indústria e de serviços. Curiosamente, em Batatais, as mudanças se deram, principalmente, na agropecuária e na indústria.

É importante destacar que as microrregiões e os setores não são desagregados. Isso implica um grau maior de generalização sobre a economia paulista, uma vez que dentro das próprias microrregiões (grupo de setores) existem municípios (atividades setoriais) com variado resultado de emprego e estrutura produtiva heterogênea.

\section{Tipologia diferencial-estrutural}

A tipologia do método diferencial-estrutural é uma maneira que melhor caracteriza as regiões de estudo. Para tanto, considera-se primeiramente as quatro variações da abordagem de Esteban-Marquillas, tais como: Variação Líquida Total (VLT), Variação Estrutural (E), Efeito competitivo (C) e Efeito de alocação (A). Em seguida, para caracterizar as atividades setoriais, analisam-se os dois componentes do Efeito de alocação (A), isto é: o componente de especialização e o componente de vantagem competitiva.

Cabe recordar que a VLT é um resultado combinado da Variação Estrutural (E), do Efeito Competitivo (C) e Efeito Alocação (A) (vide equação 1a). Assim, a VLT indica quais as microrregiões que cresceram mais ("dinâmicas") e quais cresceram menos ("não dinâmicas") que a média global (estadual) (Simões \& Melo 1998). A variação Estrutural (E) indica que uma região ganhou (perdeu) em virtude de esta estar especializada em setores dinâmicos (não-dinâmicos). O efeito competitivo (C) capta o grau de especialização do emprego na região, na qual o mesmo está interligado com a variação estrutural e o componente diferencial da região. Por fim, o Efeito de Alocação (A) aponta que o crescimento regional pode ocorrer porque a região detém e combina as suas van- 
tagens competitivas com sua especialização (transformações na variação competitiva). Com essas especificações, elaborou-se a tipologia das microrregiões paulistas para o período de 2000 e 2010 . Esta tipologia combina 14 resultados possíveis (7 para VLT positivo e 7 VLT negativo), todavia somente são exibidos os que abrangem as 63 microrregiões. A Tabela 4 e Figura 2 mostram as tipologias obtidas.

Ali observa-se que Itanhaém(56) se situa no grupo A1, de forma que todas as variações são positivas. Em linhas gerais, isto significa que a estrutura produtiva desta microrregião entre o período de 2000 e 2010 tornou-se ou manteve-se especializada em setores dinâmicos (E positivo). O efeito de Alocação (A) na economia da microrregião de Itanhaém foi positivo, com ganhos competitivos no setor de serviços e comércio. É uma microrregião litorânea onde predominam as atividades do turismo.

Tabela 4: Tipologia das microrregiões paulista pelo método shift-share

\begin{tabular}{|c|c|c|c|}
\hline Cod. & $\begin{array}{l}\text { VLT } \\
(\text { sinal })\end{array}$ & Tipologia & Microrregiões \\
\hline A1 & + & E, C, A positivas & Intanhaném (56) \\
\hline A2 & + & A positiva supera $\mathrm{E}$ e $\mathrm{C}$ negativas & Itapeva $(41)$ \\
\hline A4 & + & $\begin{array}{l}\text { E e C positivas superam A nega- } \\
\text { tiva }\end{array}$ & $\begin{array}{l}\text { Campinas (32), Caraguatatuba } \\
\text { (54), Franco da Rocha (58), Jun- } \\
\text { diai (47), Osasco (57), Presidente } \\
\text { Prudente (36), São José dos Cam- } \\
\text { pos (50) e Sorocaba (46) }\end{array}$ \\
\hline A5 & + & $\mathrm{C}$ positiva supera $\mathrm{E}$ e A negativas & $\begin{array}{l}\text { Andradina (16), Araçatuba (17), } \\
\text { Bananal (52), Barretos (9), Bauru } \\
(20) \text {, Catanduva (5), Dracena } \\
\text { (34), Fernandópolis (2), Guaru- } \\
\text { lhos (59), Ituverava (11), Mogi das } \\
\text { Cruzes (62), Mogi Mirim (31), Ou- } \\
\text { rinhos (40), Paraibuna/Paraitinga } \\
\text { (53), Pirassununga (29), Registro } \\
\text { (55), Ribeirão Preto (14), São José } \\
\text { do Rio Preto (4) e Votuporanga (3) }\end{array}$ \\
\hline A6 & + & $\begin{array}{l}\mathrm{C} \text { e A positivas superam E nega- } \\
\text { tiva }\end{array}$ & $\begin{array}{l}\text { Adamantina (35), Assis (39), } \\
\text { Avaré (22), Limeira (27), Lins } \\
\text { (19), Nhandeara (7), Novo Ho- } \\
\text { rizonte (8), Piracicaba (28), Rio } \\
\text { Claro (26), São Joaquim da Barra } \\
\text { (10) e Tatui (43) }\end{array}$ \\
\hline B1 & - & E, C, A negativas & $\begin{array}{l}\text { Auriflama (24), Birigui (15), Bra- } \\
\text { gança Paulista (48), Jales (1), Ma- } \\
\text { rília ( } 38) \text { e Piedade }(45)\end{array}$ \\
\hline B3 & - & $\begin{array}{l}\text { E e A negativas superam } C \text { posi- } \\
\text { tiva }\end{array}$ & $\begin{array}{l}\text { Araraquara (24), Batatais (15), } \\
\text { Franca (12), Jaboticabal (13), Jaú } \\
\text { (21) e São Carlos (25) }\end{array}$ \\
\hline B4 & - & $\begin{array}{l}\text { E e C negativas superam A posi- } \\
\text { tiva }\end{array}$ & $\begin{array}{l}\text { Amparo (33), São João da Boa } \\
\text { Vista (30), Tupã (37) }\end{array}$ \\
\hline B5 & - & $\mathrm{C}$ negativa supera $\mathrm{E}$ e A positiva & Santos (63) e São Paulo (61) \\
\hline B6 & - & $\begin{array}{l}\mathrm{C} \text { e A negativas superam E posi- } \\
\text { tiva }\end{array}$ & $\begin{array}{l}\text { Campos do Jordão (49) e Itaperica } \\
\text { da Serra (60) }\end{array}$ \\
\hline B7 & - & E negativa supera $\mathrm{C}$ e $\mathrm{A}$ positivas & $\begin{array}{l}\text { Botucatu (23), Capão Bonito (44) } \\
\text { e Itapetinga ( } 42 \text { ) }\end{array}$ \\
\hline
\end{tabular}

Fonte:Elaboração própria a partir dos dados da RAIS.

Os resultados do grupo A4 apontam que as microrregiões [i.e. Campi- 
nas(32), Caraguatatuba(54), Franco da Rocha(58), Jundiaí(47), Osasco(57), Presidente Prudente(36), São José dos Campos(50) e Sorocaba(46)], apesar de apresentarem efeitos alocativos negativos $(\mathrm{A})^{3}$, exibem uma estrutura produtiva por setores dinâmicos (E) e detêm um nível competitivo positivo (C). Esse dois resultados positivos contribuem, em conjunto, para uma VLT positiva. Fatores como: força de trabalho qualificada e especializada, infraestrutura econômica (por exemplo, transportes, energia e telecomunicação) e um mercado consumidor amplo contribuem para que as variações de $\mathrm{C}$ e E sejam positivas. Em particular, nas regiões de Campinas (Unicamp, PUC, EMBRAPA, ICC, LNLS, CTT etc) e São José dos Campos (ITA, INPE etc) existem universidades e centros de pesquisa de renome internacional, o que gera sinergias e spillovers de inovação para os agentes produtores locais (Montenegro \& Betarelli Junior 2008). Estes resultados têm por base os benefícios oriundos do processo de interiorização ocorrido no Estado, como o caso de Campinas, Osasco (Grande São Paulo), São José dos Campos, Sorocaba e Jundiaí.

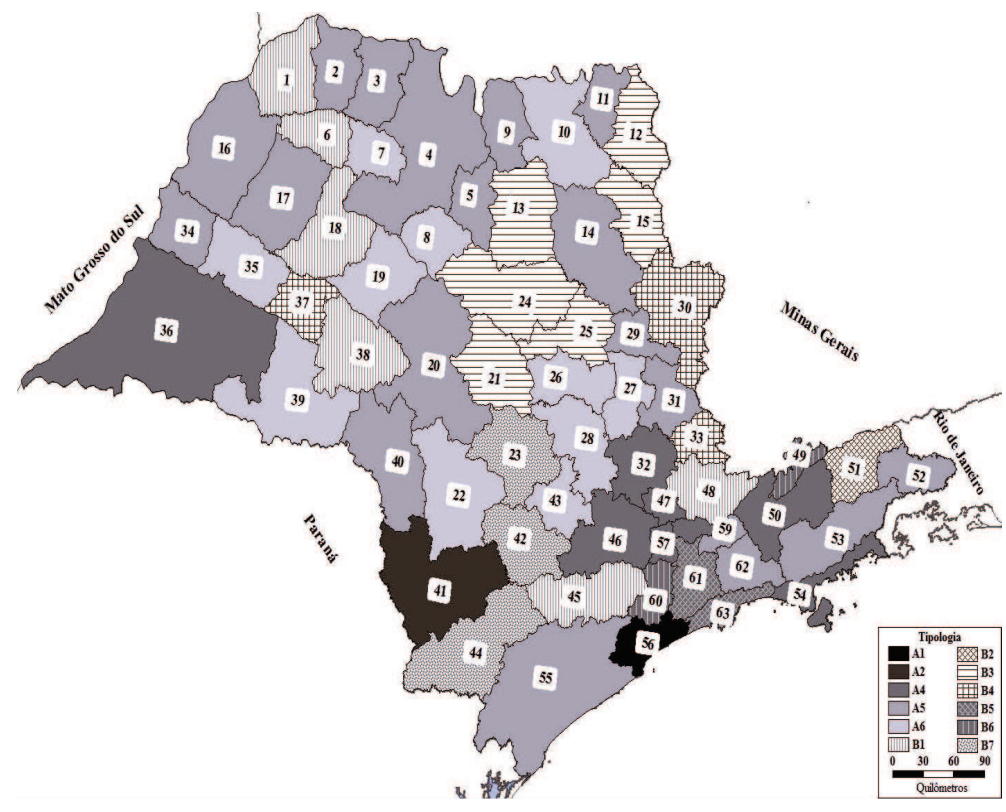

Figura 2: Tipologia das microrregiões paulista pelo método shiftshare

No grupo A5, as microrregiões [Andradina(16), Araçatuba(17), Bananal(52), Barretos(9), Bauru(20), Catanduva(5), Dracena(34), Fernandópolis(2), Guarulhos(59), Ituverava(11), Mogi das Cruzes(62), Mogi Mirim(31), Ourinhos(40), Paraibuna/Paraitinga(53), Pirassununga(29), Registro(55), Ribeirão Preto(14), São José do Rio Preto(4) e Votuporanga(3)] registraram VLT positivas em virtude dos efeitos competitivos (C). Na região de Ribeirão Preto, Dracena, Araçatuba e Fernandópolis, por exemplo, sua potencialidade é voltada na produção de açúcar e álcool, cítricos, café, milho e soja, com altos índices de mecanização e alta produtividade (Souza \& Garcia 1999). Os resultados gerais desse grupo apontam que, para algumas regiões, o ganho líquido pode ser reflexo de

\footnotetext{
${ }^{3}$ Vale destacar que a variação negativa do efeito de Alocação em Campinas se deve a uma queda de especialização no setor de serviço.
} 
dois elementos: a) do processo de interiorização (e.g. Ribeirão Preto) e, principalmente, por aproveitarem a proximidade das microrregiões como Campinas e São Paulo e Santos. Simões \& Melo (1998) destacam que as influências que provocam ganhos líquidos podem também ser oriundas de um processo conhecido como "urbanização estendida", ou seja, o transbordamento do processo de urbanização para áreas circunvizinhas.

Aliás, estes efeitos de proximidades de regiões especializadas em setores dinâmicos conjuntamente com o emprego competitivo $(\mathrm{C})$ podem se traduzir em uma VLT positiva, como o caso das microrregiões no grupo A6 [Adamantina(35), Assis(39), Avaré(22), Limeira(22), Lins(19), Nhandeara(7), Novo Horizonte(8), Piracicaba(28), Rio Claro(26), São Joaquim da Barra(10) e Tatuí(43)]. Nota-se também que, embora as microrregiões tenham problemas na sua estrutura produtiva (presença dominante de indústrias de crescimento lento), seu efeito competitivo e de alocação são positivos, mostrando que estas regiões são atrativas para uma política setorial como intuito de diversificação de suas atividades em direção aos setores dinâmicos.

Por fim, o resultado mais curioso ocorre no grupo B5. Nesse grupo, embora os efeitos de alocação (A) e a variação estrutural (E) sejam positivos, o efeito competitivo foi negativo no período de 2000 e 2010. É um resultado um pouco estranho, visto que a microrregião de São Paulo exibe uma força de trabalho altamente qualificada, principalmente, aquelas voltadas para atividades setoriais baseadas na ciência, na técnica e no conhecimento. Uma das explicações mais plausíveis reside no fato que alguns setores não encontram mais vantagens para se localizar nesta microrregião, sendo direcionados para o interior paulista (e.g. Campinas e seu entorno), que exibe efeitos competitivos e de alocação positivos (vantagens competitivas e especialização). Como resultante, atraída pela maior oferta de emprego qualificado, a mão-de-obra especializada, que antes se encontrava na microrregião de São Paulo, se movimenta para o interior. Este movimento é caracteristicamente do processo de interiorização no Estado, uma vez que ocorre por duas vias: pelo movimento das atividades setoriais e pelo movimento migratório ${ }^{4}$.

Quando se decompõem os efeitos de Alocação (A) entre vantagens competitivas e especialização para os principais grupos de setores (i.e. agropecuária, indústria e serviços), constata-se que as combinações são variadas entre as microrregiões $^{5}$. No mapa da Figura3 nota-se que a maioria das mesorregiões próximas ou vizinhas do Estado do Paraná, Mato Grosso do Sul, e Minas Gerais são especializadas e exibem vantagens competitivas para a agropecuária. Próximo com Paraná verifica-se a mesorregião do Litoral Sul Paulista (55), de Itapetininga (41, 44, 42, 43), de Bauru (22, 23, 20 e 19), de Assis (39 e 40) e Presidente Prudente (34). Quase na fronteira de Mato Grosso do Sul, constatase a mesorregião de Presidente Prudente (35 e 36), Marília (37) Araçatuba (16 e 18) e São José do Rio Preto $(1,2,3,4,6,7$ e 8$)$. Por fim, próximo a Minas Gerais, verifica-se a mesorregião de Ribeirão Preto $(9,10$ e 12) e de Campinas $(29,31,33)$. São regiões com uma cultura agropecuária fortemente voltada para o cultivo de cana-de-açúcar e do agronegócio em geral (o complexo da soja, milho, açúcar e café). A propósito, observa-se que existe um corredor que se inicia na fronteira de Mato Grosso do Sul, passando pelas mesorregiões

\footnotetext{
${ }^{4}$ Tal justificativa é corroborada por Caiado (1995). Cabe destacar que nesse movimento prevalecem forças aglomerativas e desaglomerativas que serão mais bem observadas nos resultados da ACP, adiante.

${ }^{5}$ As microrregiões são identificadas por números e a relação está descrita no Anexo 1.
} 
próximas ao Estado do Paraná. Nitidamente, este caminho corresponde os trechos ferroviários da NOVOESTE (Ferrovia Novoeste S.A), ALL (América Latina Logística do Brasil S.A.) e FERROBAN (Ferrovias Bandeirantes S.A.). Como grande parte das cargas movimentadas que transitam no Estado de São Paulo corresponde aos produtos do agronegócio, o que se observa é que as vantagens competitivas da agropecuária nestes locais parecem ser influenciadas pela infraestrutura ferroviária.

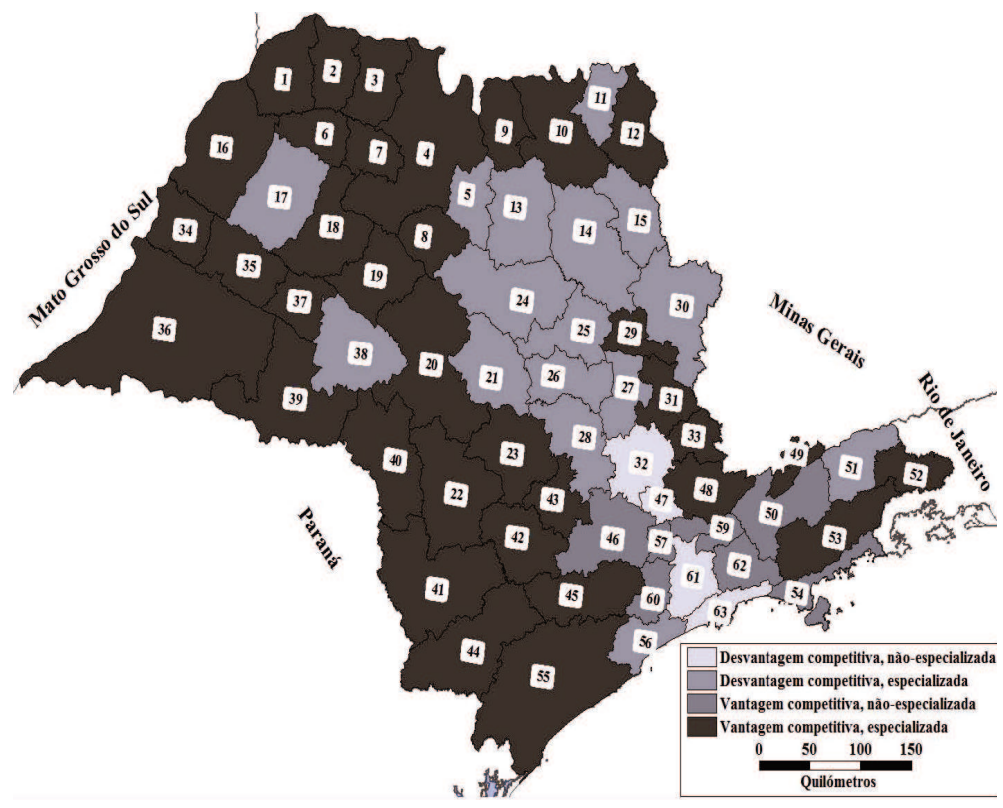

Figura 3: Efeito de alocação desagregado para a agropecuária

Além das microrregiões de São José do Rio Preto (4), Amparo (33), Votuporanga (3), Mogi Mirim (31), Bragança Paulista (48), Ourinhos (40), Tatuí (43), Lins (19), Fernandópolis (2) e Novo Horizonte (8) serem especializadas e exibirem vantagens competitivas no setor da agropecuária, as mesmas também revelam vantagens competitivas e são especializadas no setor industrial ( $F i$ gura4). A microrregião de São José do Rio Preto representa um dos principais polos industriais e de serviços do interior de São Paulo. O distrito industrial desta microrregião é dinâmico, composto por micro, pequenas e médias empresas. Além disso, a microrregião engloba o chamado Setor de Minidistritos e Centro Incubador de Empresas ${ }^{6}$ onde estão instaladas mais de 740 empresas de vários setores. Por outro lado, embora São José do Rio Preto seja especializada e revele vantagens competitivas à agropecuária, este setor é o menos relevante na economia desta microrregião. A economia de Bragança Paulista, por seu turno, engloba como principais atividades a agricultura e indústrias de celulose, alimentícia e eletrônica. A microrregião de Votuporanga tem o setor Moveleiro, Implementos Rodoviários e Metalurgia como principais atividades da indústria (predominam indústrias weberianas e tradicionais).

Na 4 também observa-se, também, uma aglomeração espacial no tocante às vantagens competitivas e de especialização do setor industrial. Nota-se

\footnotetext{
${ }^{6}$ Foi elaborado pela Secretaria Municipal de Planejamento e Gestão Estratégica, no final de 1983
} 


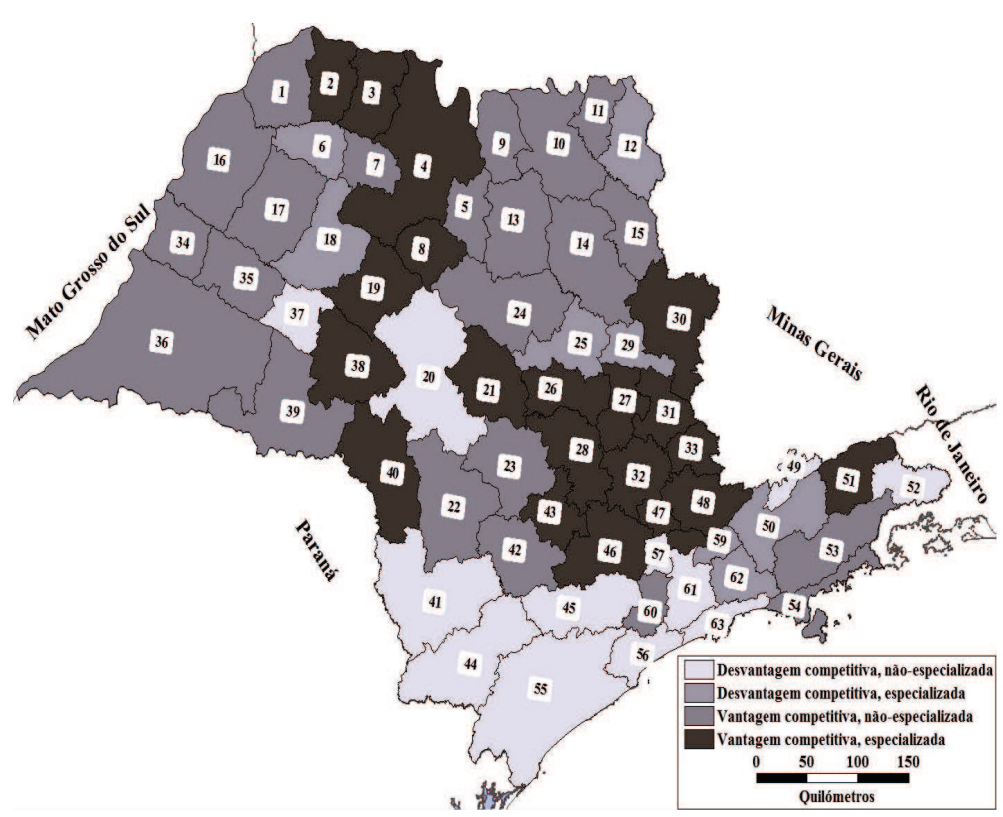

Figura 4: Efeito de alocação desagregado para a indústria

que 10 microrregiões circunvizinhas ou próximas [Jaú (21), Rio Claro (26), Limeira (27), Piracicaba (28), Sorocaba (46), São João da Boa Vista (30), Mogi Mirim (31), Amparo (33) e Bragança Paulista (48)] à microrregião de Campinas (32) formam um aglomerado espacial. Isto ratifica, sem dúvida, o resultado do processo de interiorização da indústria tratado por Azzoni (1986), Cano (1992) e Diniz $(1993,1995,2002)$. Nessas regiões observa-se uma moderna infraestrutura de transporte (e.g. Rodovias dos Bandeirantes, Anhanguera e D. Pedro I) que interliga essas microrregiões, além de setores intensivos em conhecimento, uma concentração de P\&D e um mercado de trabalho complexo e diversificado (por exemplo Campinas).

Os efeitos de alocação da microrregião de São Paulo, quando analisados o setor da agropecuária e industrial, são positivos. Isso porque o nível de emprego entre 2000 e 2010 desses setores cresceu menos que a média do Estado (desvantagem competitiva) e porque o seu emprego em 2000 foi menor que o seu homotético (não-especializado).

A grande maioria das microrregiões da economia paulista (39 ao todo) apresenta vantagens competitivas no setor de Serviços (Figura5). Contudo, grande parte dessas regiões não são especializadas, o que gera um efeito de Alocação (A) negativo. Apenas as microrregiões de Itanhaém (56), Osasco (57) e Caraguatatuba (54) se demonstram especializadas e ao mesmo tempo produzem vantagens competitivas para o setor de serviços. Em virtude da desconcentração industrial para outras regiões, na economia da microrregião de Osasco o setor de serviços e comércio veem se tornando a principal atividade econômica (segundo IBGE, cerca de 65\% do PIB de 2008 corresponde a serviços, representando a sexta maior microrregião do Estado). O setor de serviços em Itanhaém, por seu turno, registrou uma participação de $77 \%$ do PIB da microrregião em 2008 (segundo do ranking), tendo o turismo regional como principal atividade.

Em linhas gerais, observa-se um ganho líquido (VLT) de 40 microrregiões 


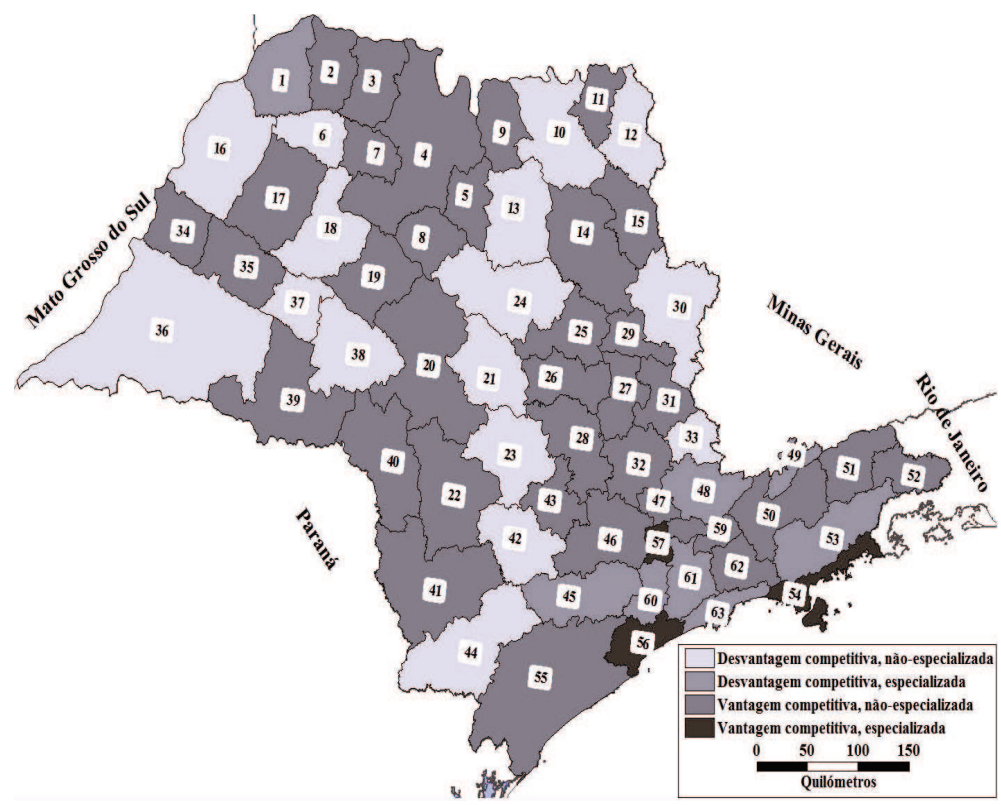

Figura 5: Efeito de alocação desagregadopara o setor de serviços

paulista quando se analisa do período de 2000 e 2010. Dessas 40, apenas Itanhaém exibiu, em todos os componentes da VLT, valores positivos. Essa microrregião é uma região especializada e com vantagens competitivas para a atividade de serviços. Por outro lado, quando analisados os componentes do efeito de Alocação da agropecuária, observou-se microrregiões especializadas e com vantagens competitivas próximas da fronteira do Paraná, Minas Gerais e Mato Grosso do Sul. Verificou-se que existe uma aglomeração espacial de regiões especializadas e com vantagens competitivas para indústria, principalmente, no entorno de Campinas. Estes resultados parecem ser reflexo do processo de interiorização das atividades econômicas, intensificado nos anos 1980 e 1990, no qual são beneficiadas diretamente as microrregiões de Campinas, São José dos Campos, Sorocaba, Ribeirão Preto (agricultura moderna), Santos e Jundiaí. Um exemplo mais evidente dos efeitos desse processo é que tais regiões registraram crescimento acima da média do Estado (vantagens competitivas) e, sobretudo, acima do crescimento da microrregião da capital paulista.

\subsection{Análise Multivariada: ACP e Clusters}

A seção anterior evidenciou as microrregiões que exibiram ganhos (ou perdas) líquidos oriundos da variação Estrutural (composição da estrutura produtiva), variação de Competitividade (emprego especializado ou não-especializado) e da variação de Alocação (positivo ou negativo). Entretanto, falta analisar se as microrregiões que apresentaram VLT positivo (negativo) são as mesmas que exibem fatores urbanos aglomerativos e/ou desaglomerativos.

Dessa maneira, utiliza-se o método de ACP para as 63 microrregiões paulistas no ano de 2010, considerando as 12 variáveis originais (vetor aleatório). Vale destacar que o método ACP fornece um número de componentes principais igual ao número de variáveis originais, todavia é conveniente considerar 
um número mínimo de componentes que contenha a maior parte da variabilidade do vetor aleatório. Assim, a Tabela 5 mostra a contribuição individual e acumulada dos componentes principais.

Tabela 5: Total de Variância das 63 microrregiões paulistas

\begin{tabular}{ccc}
\hline & \multicolumn{2}{c}{ Variação Correspondente (\%) } \\
Componentes & Individual & Acumulado \\
\hline 1 & 43,38 & 43,38 \\
2 & 19,05 & 62,43 \\
3 & 12,45 & 74,88 \\
4 & 6,59 & 81,47 \\
5 & 4,58 & 86,05 \\
6 & 4,46 & 90,51 \\
7 & 2,96 & 93,46 \\
8 & 2,37 & 95,84 \\
9 & 1,79 & 97,63 \\
10 & 1,27 & 98,90 \\
11 & 1,01 & 99,91 \\
12 & 0,09 & 100,00 \\
\hline
\end{tabular}

Fonte:Elaboração Própria

O três primeiros componentes significam em conjunto $74,8 \%$ da variância total dos dados. Observa-se que existe uma quebra entre o terceiro e quarto componente. O primeiro componente, que representa $43,3 \%$ da variância, aponta nitidamente para as forças opostas entre as economias e deseconomias de aglomeração. Pode-se dizer que esse componente capta os efeitos líquidos das economias de urbanização e localização nas microrregiões paulistas, pois coeficientes como CESP, ANALFAB e POBREZ apresentam sinais negativos e denotam as deseconomias urbanas (Tabela 6). Ademais, é interessante notar que, se de um lado a variável MERCADO denota o poder aquisitivo do mercado, de outro lado, a variável POBREZ se traduz no mais baixo poder aquisitivo. Esse componente também mostra que as microrregiões especializadas em estruturas produtivas de baixa escala e diversa a do Estado também apresentam um nível de pobreza e analfabetismo alto. Em termos de política setorial, esse resultado parece contribuir no sentido de evidenciar a necessidade de diversificação das atividades econômicas em determinadas microrregiões, com o objetivo de reverter a predominância das deseconomias de urbanização. Isso se torna mais evidente pelos sinais positivos dos demais coeficientes, sendo a qualificação da força de trabalho, a oferta de serviços produtivos, o poder de compra do mercado local e a presença dos setores dinâmicos como as principais variáveis a serem levadas em consideração por tais políticas.

No segundo componente, responsável por $19,0 \%$ da variabilidade do vetor aleatório, três coeficientes são significativos e negativos (GINDUST, MSINDTR e QLTRAD). Esse componente tende a captar as economias de urbanização advindas de atividades produtivas não-industriais, como as economias geradas pelo tamanho do mercado local e pela oferta de serviços produtivos. Tendo em vista que o grau de especialização apresenta sinal negativo, o mercado local e o setor de serviços revelam-se diversificado e amplo. 
Tabela 6: Coeficientes dos Componentes Principais†

\begin{tabular}{lccc}
\hline Variáveis & Componente 1 & Componente 2 & Componente 3 \\
\hline GINDUST & 0.203 & -0.565 & \\
MSINDIR & 0.245 & -0.441 & \\
MERCADO & 0.370 & 0.215 & \\
FESPEC & 0.340 & & 0.298 \\
SERVIÇOS & 0.355 & 0.191 & \\
ECESCALA & 0.267 & & 0.491 \\
QLWEB & 0.306 & & -0.170 \\
QLDINAM & 0.368 & & \\
QLTRAD & & -0.578 & \\
CESP & -0.336 & -0.181 & 0.578 \\
ANALFAB & -0.187 & & 0.504 \\
POBREZ & -0.263 & & \\
\hline Fonte:Elaboração própria & & \\
† Os valores ocultos situam-se abaixo de 0,15 &
\end{tabular}

O terceiro componente, que representa $12,4 \%$ da variância dos dados, mostra que as microrregiões tendem a atrair uma estrutura produtiva mais diversificada de tal forma que absorva a oferta de trabalho no mercado local (qualificado e não-qualificado). De um lado, o coeficiente positivo da variável ANALFAB se revela como uma força de atração para atividades econômicas não demandantes de qualificação, pois tal variável parece se traduzir num baixo custo da força de trabalho. Por outro, o coeficiente positivo FESPEC sugere uma força de atração ou benefícios para os setores mais intensivos em trabalho qualificado. Nessas microrregiões o coeficiente da variável ECESCALA aponta que as atividades, ali instaladas, obtêm economias de escala que geralmente são externalizadas nas suas transações econômicas. Este fato pode atrair as atividades para absorver parte destes benefícios e aproveitarem-se da força de trabalho. Notadamente, se a força de trabalho é o principal fator aglomerativo nesse componente, logo esse fator vale menos para as indústrias weberianas - QLWEB- orientadas para as fontes de matéria-prima.

Dadas as descrições dos componentes principais de maior variância, é possível realizar uma representação gráfica a fim de averiguar as similaridades e diferenças existentes entre as microrregiões em cada quadrante cartesiano (Figura6).

No quadrante superior esquerdo $(\mathrm{Q} 1)$ estão às microrregiões com alto nível de pobreza e analfabetismo e que ao mesmo tempo apresentam um alto grau de especialização. Essas regiões têm por natureza um baixo grau de industrialização e suas atividades não geram economias de escala. Além desses fatores adversos, as suas economias têm um reduzido mercado interno (poder de compra) e uma baixa (ou inexistente) força de trabalho especializada. Na composição das suas estruturas industriais, observa-se que setores dinâmicos e indústrias weberianas estão ausentes. Tal caracterização é mais evidente para as microrregiões de Itanhaém, Caraguatatuba, Campos do Jordão, Registro e Capão Bonito.

No quadrante inferior esquerdo $(\mathrm{Q} 2)$, estão às microrregiões especializadas em setores tradicionais (intensivo de trabalho), nas quais o nível de pobreza e analfabetismo são acentuados. Na sua economia o poder de compra é 


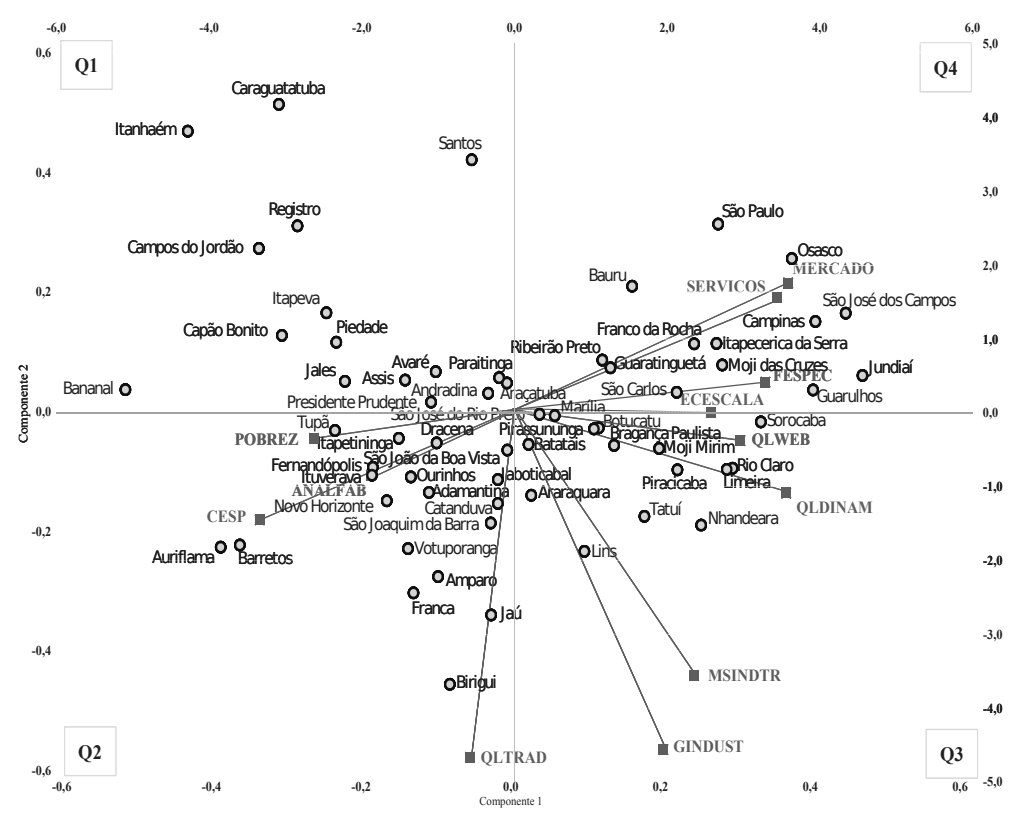

Figura 6: Distribuição das microrregiões em torno dos dois primeiros componentes

baixo (mercado) e o nível de qualificação da força de trabalho é reduzido. Isto reforça a ausência de setores dinâmicos e indústrias weberianas. A principal diferença com o Q1 é que neste quadrante as microrregiões têm um maior grau de industrialização, voltadas principalmente para setores tradicionais. As microrregiões de Auriflama, Novo Horizonte, Ourinhos e Barretos são bons exemplos desse Q2. Aliás, com um menor grau de analfabetismo e pobreza e com maior especialização em setores tradicionais, destacam-se as microrregiões de Birigui, Lins e Franca. A microrregião de Franca, por exemplo, é altamente especializada na produção de calçados e derivados do couro.

No quadro inferior direito (Q3) concentram-se as microrregiões com maior grau de industrialização de tal forma que geram e usufruem de economias de escala, em especial, nos setores dinâmicos e nas indústrias weberianas. Em geral, o setor da indústria de transformação configura-se como a principal atividade econômica nessas microrregiões, cuja característica é a presença de fortes efeitos de encadeamentos com uma ampla cadeia produtiva local. $\mathrm{Na}$ sua economia existe uma predominância de trabalho qualificado e certo vigor do mercado local. Ademais, o grau de analfabetismo e de pobreza é baixo. Limeira, Sorocaba, Mogi Mirim, Rio Claro, Piracicaba e Tatuí são bons exemplos desta caracterização econômica, por serem altamente industrializadas e por exibirem economias de localização e urbanas.

No último quadrante superior direito (Q4), encontram-se as microrregiões que exibem uma estrutura industrial complexa, sobretudo, por setores dinâmicos e poucas indústrias weberianas. São microrregiões com alto poder aquisitivo no mercado local e com uma grande concentração de oferta de serviços produtivos. O grau de industrialização é bem menor quando comparado com as microrregiões do Q3. Isto aponta para o fato de que existem municípios das microrregiões do Q4 que estão voltadas, sobretudo, para outras atividades como a agropecuária. Em suma, as microrregiões do Q4 apresentam uma es- 
trutura de atividades altamente diversificada e complexa, quando comparado com os demais quadrantes, visto que os seus municípios são especializados na agropecuária, indústria e serviços. Esta observação é reforçada pela direção oposta da variável CESP (grau de especialização). Ao contrário do quadrante (Q3), as economias urbanas são proeminentes seguidas pelas economias de localização. As principais microrregiões com estas características são: São José dos Campos, Campinas, Osasco, Mogi das Cruzes, Jundiaí, Guarulhos e São Paulo.

Para auxiliar a tipologia que evidencia as características de efeitos locacionais das microrregiões paulistas extraídas dos resultados do método ACP, necessita-se da técnica de agrupamento hierárquico aglomerativo da análise de Cluster. Da mesma forma que o método ACP, a análise de Cluster considera as 12 variáveis descritas e revela como as microrregiões paulistas podem ser agrupadas pelas influências das suas similaridades. Essa técnica fornece uma maior precisão de análise para as caracterizações das regiões com base nos resultados da $\mathrm{ACP}^{7}$.

Os resultados da técnica de cluster, apresentados na Figura7, dividem as microrregiões paulistas em 4 grupos (G1, G2, G3 e G4). Dentre esses quatros grupos, o G1 engloba as microrregiões com situação econômica mais adversa, sendo suas economias dominadas por deseconomias urbanas: maior grau de pobreza e analfabetismo. Essas microrregiões apresentam um nível alto de especialização em setores com efeito de encadeamento baixo e que, na maioria da vezes, não obtêm economias de escala no processo produtivo. Nesse mesmo grupo, com maior grau de industrialização, estão as microrregiões Franca, Jaú e Birigui. Essas três microrregiões detêm na sua estrutura industrial a predominância de atividades tradicionais intensivas em trabalho (baixa qualificação da força de trabalho), com um menor grau de analfabetismo e pobreza. Em linhas gerais, observa-se que o G1 engloba grande parte das microrregiões do quadrante $2(\mathrm{Q} 2)$.

No G3 estão as microrregiões caracterizadas no quadrante 1 (Q1), com alto grau de analfabetismo, pobreza e certa especialização na sua estrutura produtiva. As suas economias são caracterizadas pela grande dependência de outras atividades (agropecuária e serviços), o que se traduz no mais baixo grau de industrialização. Caraguatatuba e Itanhaém, além da adversidade das deseconomias urbanas, são microrregiões dependentes do comércio e turismo, ratificando a inexpressiva cadeia produtiva da indústria nessas regiões. $\mathrm{O}$ inexpressivo grau de industrialização também se confirma em Santos, tendo a economia dessa microrregião um grau de analfabetismo e pobreza menor.

As microrregiões do G2 se encontram numa melhor situação, pois detêm uma estrutura produtiva mais diversificada e voltada para indústrias dinâmicas e weberianas, de forma que imperam nas suas economias os fatores aglomerativos (alto poder aquisitivo, alta oferta de serviços produtivos, grande elos de ligação da indústria, economias de escala e força de trabalho qualificada). Elas são, na maioria, correspondentes às microrregiões dos quadrantes 3 e 4. Essas características também predominam nas microrregiões do G4. Aliás, os resultados associados entre ACP e cluster revelam que as microrregiões do G4 são aquelas que estão em melhores condições econômicas no Es-

\footnotetext{
${ }^{7}$ Tal técnica utilizou a distância euclidiana e usou o método Ward para o agrupamento de casos (microrregiões). O coeficiente de cluster, que mede o quanto o agrupamento das microrregiões condiz com as 12 variáveis, registrou um valor de 0,88 .
} 


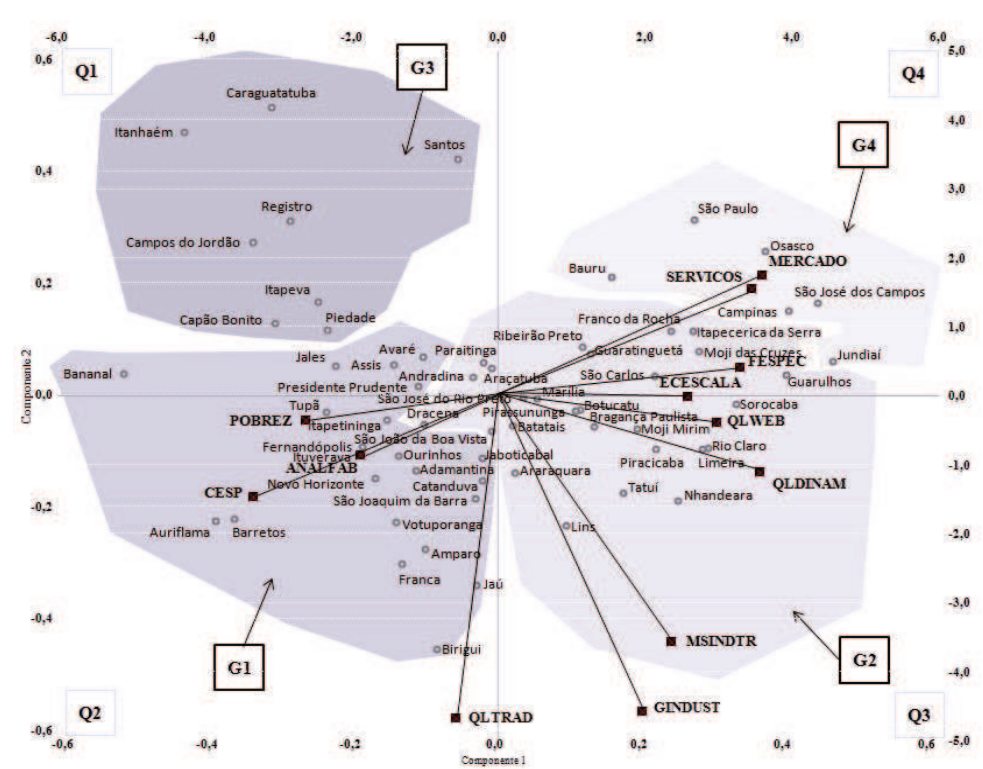

Figura 7: Cluster hierárquico das microrregiões paulistas

tado de São Paulo. Dito em outras palavras, os resultados apontam que essas microrregiões apresentam economias com estrutura produtiva mais diversificada do Estado de São Paulo.

Como forma de melhor ilustrar no espaço os 4 grupos que caracterizam as microrregiões paulista, foi elabora a Figura8.

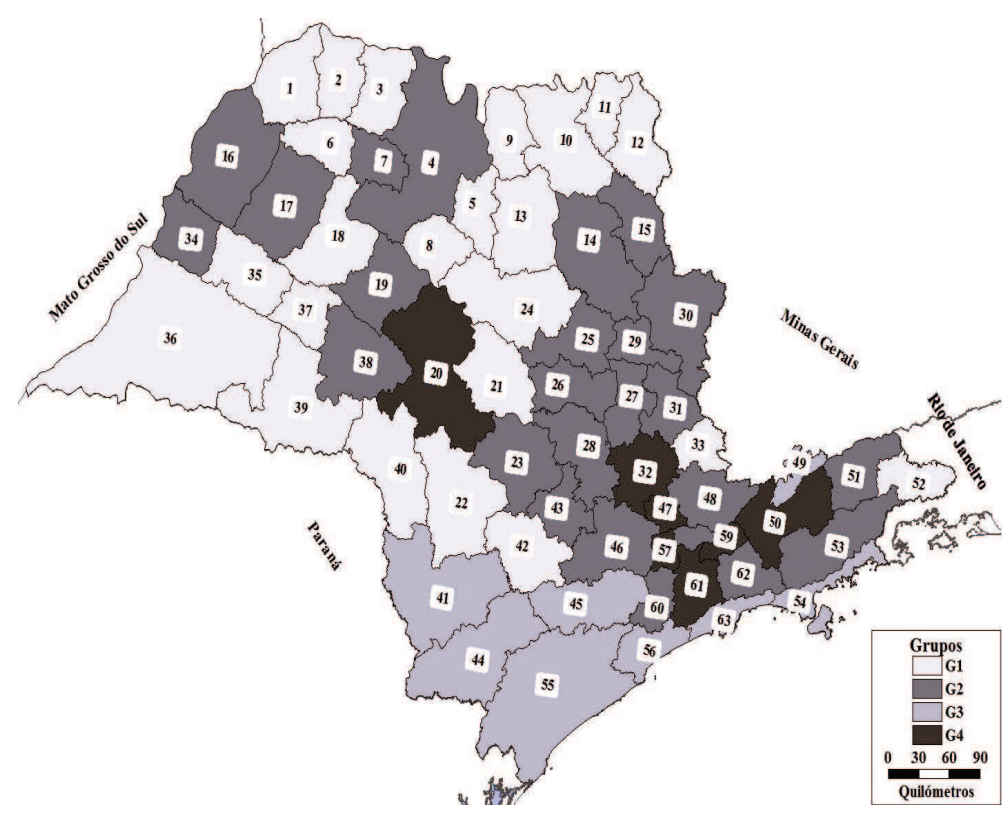

Figura 8: Cluster das microrregiões do Estado de São Paulo (2010)

É interessante notar no mapa dessa figura que as microrregiões que exibem 
uma estrutura industrial complexa, sobretudo, a) por setores dinâmicos e indústrias weberianas; b) por um alto poder aquisitivo no mercado local; c) por uma grande concentração de oferta de serviços; e d) por uma predominância de trabalho qualificado, formam um aglomerado urbano entorno de São Paulo e das principais regiões beneficiadas do processo de interiorização da economia paulista, isto é, Sorocaba, São José dos Campos, Ribeirão Preto e Campinas. Pode-se afirmar que o campo aglomerativo se configura mais amplo que a urbanização no território paulista e, portanto, economias de regionalização fluem mais entre aquelas microrregiões que foram, direta ou indiretamente, influenciadas por tal processo.

\section{Considerações Finais}

Este trabalho pretendeu oferecer contribuições acerca das características das microrregiões paulistas por meio de uma análise da dinâmica de crescimento do emprego e dos principais fatores locacionais de urbanização no período de 2000 e 2010. Para atingir este propósito buscou-se conciliar o Método Diferencial-Estrutural (shift-share), a Análise de Componentes Principais (ACP) e a Análise de Cluster.

Em linhas gerais, observa-se que o processo de interiorização das atividades econômicas, mormente nos anos 1980 e 1990, inicialmente beneficiou diretamente Campinas, São José dos Campos, Sorocaba, Ribeirão Preto (agricultura moderna), Santos (Baixada Santista) e Jundiaí. Mais que isto, provocou uma desconcentração concentrada na estrutura da economia do Estado. Notase que o entorno imediato dessas regiões apresentam, devido as economias de regionalização, fatores aglomerativos que, no mínimo, continuam a promover esse movimento. Dito em outras palavras, os resultados indicam que o campo aglomerativo se configura mais amplo que a urbanização no território paulista e, portanto, economias de regionalização fluem mais entre aquelas microrregiões que foram, direta ou indiretamente, afetadas por tal processo.

A diversificação da estrutura produtiva parece ser a melhor estratégia em termos de políticas industrial e regional para alavancar as economias aglomerativas (localização e urbana) nas microrregiões especializadas em atividades econômicas com fraco encadeamento local, pois geralmente essas apresentam também um alto nível de pobreza e analfabetismo. Parece ser necessária, como no processo de interiorização da indústria no final dos anos 1970, uma grande articulação entre as esferas privadas e públicas sobre as microrregiões periféricas não-industrializadas, de forma que os efeitos dos investimentos privados e públicos sejam localmente endogeneizados, minimizando os vazamentos dos efeitos de encadeamento. Para tanto, a qualificação da força de trabalho parece estratégia interessante no sentido da atração de indústrias dinâmicas e, por efeitos indiretos, das weberianas. Como conseguinte, potencialmente têm-se a ampliação do mercado local e ofertas de serviços produtivos. A formulação de políticas regionais, com o objetivo de amenizar as desigualdades regionais existentes no Estado de São Paulo, pode traçar estratégias priorizando as microrregiões onde as deseconomias de urbanização predominam, sobretudo, àquelas que registraram efeitos competitivos e de alocação positivos.

Finalizando, esse trabalho procura auxiliar na caracterização da economia paulista na década de 2000, apontando as principais microrregiões que de- 
têm um dinamismo setorial diferenciado e seus fatores aglomerativos e desaglomerativos. Essas informações podem auxiliar e subsidiar as decisões dos planejadores públicos para a elaboração de políticas regionais.

\section{Referências Bibliográficas}

Andrade, T. A. (1989), Métodos estatísticos e econométricos aplicados à economia regional, in 'Economia Regional: Teorias e métodos de análise', Fortaleza: BNB.

Azzoni, C. R. (1986), Indústria e reversão da polarização no brasil, Technical report, FIPE-USP.

Caiado, A. S. C. (1995), 'Dinâmica socioespacial e a rede urbana paulista', São Paulo em Perspectiva 9.

Cano, W. (1977), Raízes da concentração industrial em são paulo, Technical report, São Paulo: Hucitec.

Cano, W. (1992), São paulo no limiar do século, Technical report, Fundação Seade - SEPLAN.

Diniz, C. C. (1993), 'Desenvolvimento poligonal no brasil: nem desconcentração, nem contínua polarização', Revista Nova Economia 2.

Diniz, C. C. (1995), Dinâmica regional recente da economia brasileira e suas perspectivas, Technical report, IPEA.

Diniz, C. C. (2002), A nova configuração urbano-industrial no brasil, in 'Unidade e fragmentação: a questão regional no Brasil', Perspectiva.

Gonçalves, E., Perobelli, F. S. \& Lauer, A. A. (2000), O caráter espacial do desenvolvimento de minas gerais: um estudo de alternativas locacionais através do método diferencial-estrutural, in 'IX Seminário sobre a Economia Mineira, 2000, Diamantina. Anais do IX Seminário sobre a Economia Mineira', CEDEPLAR.

Haddad, E. A. \& Perobelli, F. S. (2002), 'Integração regional e padrão de comércio dos estados brasileiros, unidade e fragmentação: A questão regional no brasil', Perspectiva .

Haddad, P. R. (1989), Economia regional, teorias e métodos de análise., Technical report, Fortaleza: BNB.

Leme, R. (1982), A contribuição à teoria da localização industrial, Technical report, FIPE.

Lemos, M. B., Moro, S., Crocco, M. \& Biazi, E. (2003), 'A dinâmica urbana das regiões metropolitanas brasileiras', Revista Economia Aplicada 7, 213-244.

Lösch, A. (1954), The economics of location, Technical report, Yale: Yale University.

Manly, F. J. B. (1986), Multivariate statistical methods. a primer, Technical report, London: Chapman and Hall. 
Martins, N. S. F. (2003), Dinâmica urbana e perspectivas de crescimento itabira, minas gerais, Master's thesis, Universidade Federal de Minas Gerais.

Mingoti, S. A. (2007), Análise de dados através de métodos de estatística multivariada: Uma abordagem aplicada., Technical report, Belo Horizonte: UFMG.

Montenegro, R. L. G. \& Betarelli Junior, A. A. (2008), 'Análise e investigação dos fatores determinantes da inovação nos municípios de são paulo.', Revista Brasileira de Estudos Regionais e Urbanos 2.

Patarra, N. \& Baeninger, R. (1994), Regionalização de são paulo: novas tendências ou consolidação dos processos recorrentes? relatório de pesquisa do projeto a nova realidade socioeconômica do estado de são paulo., Technical report, Campinas: Unicamp.

Pereira, F. M. (2002), Cidades médias brasileiras: uma tipologia a partir de suas (des)economias de aglomeração, Master's thesis, Universidade Federal de Minas Gerais (CEDEPLAR/UFMG).

Pereira, F. M. \& Lemos, M. B. (2003), 'Cidades médias brasileiras: características e dinâmicas urbano-industriais.', Pesquisa e Planejamento Econômico, Rio de Janeiro 33.

Seade, F. (1992), O novo retrato de são paulo - avaliação dos primeiros resultados do censo demográfico de 1991, Technical report, SEADE.

Simões, R. F. \& Melo, V. S. (1998), Dinâmica das atividades agropecuárias em minas gerais, Technical report, Belo Horizonte: DCE/UFMG.

Souza, M. C. \& Garcia, R. (1999), Sistemas locais de inovação em são paulo, in 'Globalização e Inovação Localizada: Experiências de Sistemas Locais no Mercosul’, Brasília: IBICT/MCT.

Von Thünen, J. H. (1966), Isolated state: an english editon of der isolierte staat., Technical report, Oxford: Pergamon.

\section{Apêndice A Tipologia dos resultados do método diferencial-estrutural}




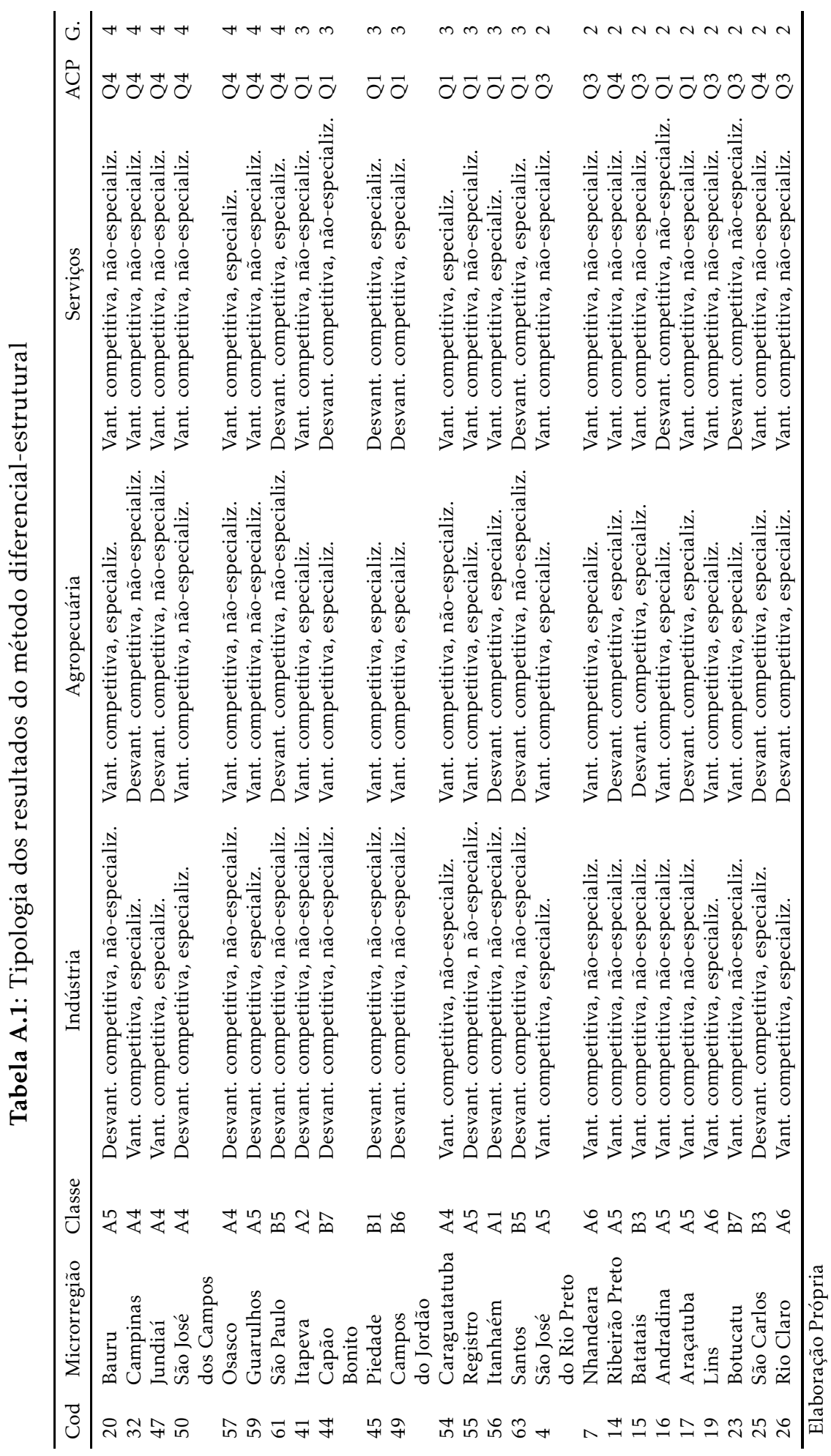




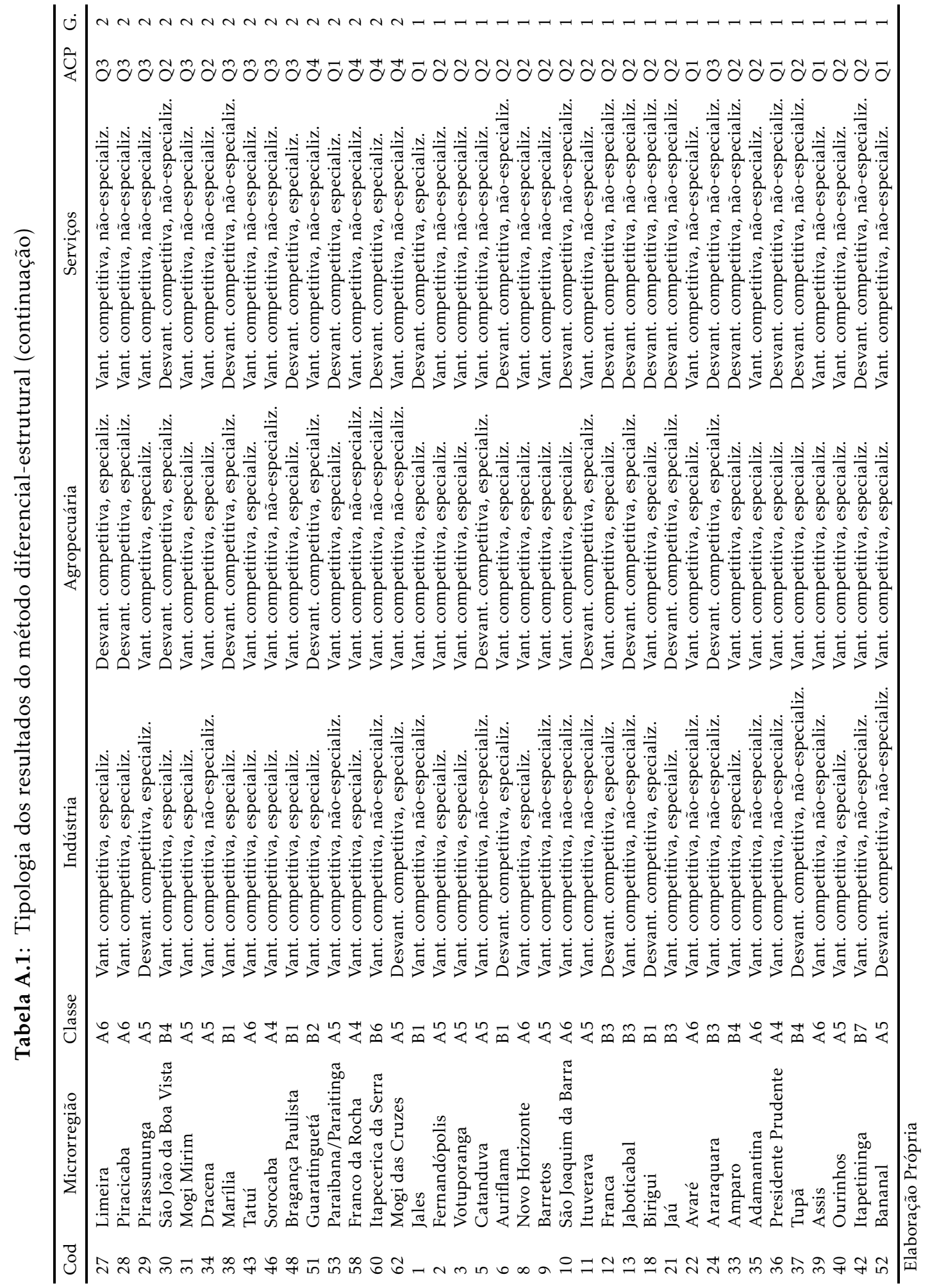

